\title{
Residual Flexural Capacity of Corroded Prestressed Reinforced Concrete Beams
}

\author{
Mahdi Kioumarsi ${ }^{1, *(\mathbb{D}}$, Armando Benenato ${ }^{2}$, Barbara Ferracuti ${ }^{2}\left(\mathbb{D}\right.$ ) and Stefania Imperatore ${ }^{2}$ (D) \\ 1 Department of Civil Engineering and Energy Technology, OsloMet-Oslo Metropolitan University, \\ Pilestredet 35, 0166 Oslo, Norway \\ 2 Department of Civil Engineering, “Niccolò Cusano” University, Via Don Carlo Gnocchi, 3, 00166 Rome, Italy; \\ armando.benenato@unicusano.it (A.B.); barbara.ferracuti@unicusano.it (B.F.); \\ stefania.imperatore@unicusano.it (S.I.) \\ * Correspondence: mahdik@oslomet.no; Tel.: +47-6723-8745
}

Citation: Kioumarsi, M.; Benenato,

A.; Ferracuti, B.; Imperatore, S.

Residual Flexural Capacity of

Corroded Prestressed Reinforced

Concrete Beams. Metals 2021, 11, 442.

https://doi.org/10.3390/met11030442

Academic Editor:

Charis Apostolopoulos

Received: 31 January 2021

Accepted: 2 March 2021

Published: 7 March 2021

Publisher's Note: MDPI stays neutral with regard to jurisdictional claims in published maps and institutional affiliations.

Copyright: (c) 2021 by the authors. Licensee MDPI, Basel, Switzerland. This article is an open access article distributed under the terms and conditions of the Creative Commons Attribution (CC BY) license (https:// creativecommons.org/licenses/by/ $4.0 /)$.
Abstract: Infrastructures and industrial buildings are commonly exposed to aggressive environments and damaged by corrosion. In prestressed reinforced concrete structures, the potential risks of corrosion could be severe since reinforcements are already subjected to high amounts of stress and, consequently, their load-bearing capacity could abruptly decrease. In recent years, some experimental studies have been conducted to explore the flexural behavior of corroded pretensioned reinforced concrete (PRC) beams, investigating several aspects of residual structural performance. Although many studies have been done in this area, there is no concise paper reviewing the state-of-theart research. Accordingly, the main objective of this paper is to provide a review of the available experimental tests for residual capacity assessment of corroded PRC beams. Based on the state-ofthe-art review, a degradation law for the flexural strength of corroded PRC beams is suggested.

Keywords: corrosion degradation; prestressed reinforced concrete beam; corroded strands; residual flexural capacity

\section{Introduction}

Corrosion is one of the predominant causes of deterioration in reinforced concrete (RC) structures. The primary effects of corrosion on RC elements are cross-section loss of steel reinforcement, decayed mechanical properties of reinforcement, reduction in bond strength between reinforcement and concrete, and reduction in concrete compressive strength due to the cracking [1-5]. These mechanical damages result in the reduced structural capacity of RC elements and subsequently of the whole structure, as highlighted by several experimental and numerical studies carried out in the past few decades [6-9].

In prestressed $\mathrm{RC}$ structures, the potential risks of corrosion would be more severe than the conventional RC structures, as shown by several damage cases, which have occurred in European countries [10-14]. In the prestressed elements, the combination of applied stress and the cross-section loss of reinforcements due to corrosion could enhance the risk of brittle failure $[15,16]$. Moreover, stress corrosion cracking and hydrogen embrittlement of prestressed steel strands are other factors that might lead to a brittle failure [17-20].

Recent collapses of prestressed RC structures due to corrosion put the safety of the elements under question [11-15,21-25]. Examples include the partial collapse of Berlin Congress Hall in 1980 due to the combination of corrosion and stress concentration in the tendons (stress corrosion cracking, SCC), the Ynys-y-Gwas Bridge in the UK, which failed in 1985, and the Saint Stefano Bridge in 1990, which collapsed due to the pitting corrosion of prestressing strands [11,13,22]. More recently, the Polcevera Viaduct in Genoa, which was in service for over 50 years, collapsed, likely due to the combined effects of corrosion and fatigue [23-25]. 
Although scientific efforts are being devoted to the assessment of the residual structural performance of prestressed RC members damaged by corrosion [26-28], few experimental studies have been conducted to explore the flexural behavior of corroded pretensioned reinforced concrete (PRC) beams [29-47]. The beams realized with the pretensioning technique, where the strands are adherent to the concrete, respond differently to the corrosion phenomenon with respect to the case of beams realized with the post-tensioning technique $[38,48]$. In fact, once corrosion occurs, in pretensioning, the variation in bonds between strands and concrete influences the state of coaction, which does not occur in post-tensioning. Therefore, in the latter, the reduction in bending capacity is only due to the cross-sectional reduction of prestressing strands. While in pretensioned beams, the variation of bond strength observed in the corroded strands influences the structural performance. Nevertheless, since the strand-to-concrete interaction after the corrosion degradation has not yet been assessed, the observed prestressing loss cannot be explicitly considered in relation to the bond strength decay, and the flexural behavior of corroded PRC beams can be interpreted only from a phenomenological point of view.

The main objective of the present paper is to provide a state-of-the-art review on experimental tests assessing the flexural capacity of corroded PRC beams. With this aim, the results of the experimental studies are collected and reviewed to summarize the corrosion effects on the flexural capacity and failure mechanisms of corroded PRC beams. Furthermore, the data from the collected experimental tests are analyzed and, when possible, compared. The residual flexural strength of the corroded PRC beams is therefore reported as a function of the mean corrosion level, defining the first attempt of degradation law. In view of the limited number of beam tests, their diversities and the complexity of the phenomenon, the scattering of the experimental results from the proposed relationship are significant. Therefore, a greater effort should be made by the scientific community to enlarge the database of experimental results on corroded PRC beams. In this way, reliable models capable of predicting the capacity of corroded PC beams, at least in terms of resistance, could be properly calibrated.

\section{Review of Performed Experimental Tests on Corroded PRC Beams}

Despite the significance of this issue, few experimental studies have focused on the effect of corrosion on pretensioned reinforced concrete beams in flexure. This section presents an extensive review of these existing works. In comparison with ordinary RC beams, few experimental researches have been conducted to evaluate the structural behavior of the PRC beams damaged by corrosion; a total of 19 papers were found in the scientific literature concerning the investigated topic. In these studies, the effects of corrosion on cracking, residual capacity, ductility and types of failure in PRC beams have been investigated. The main outcomes of the collected experimental campaigns, i.e., reduction in load-bearing capacity $(\Delta R)$, ductility $(\mu)$ and observed failure mode (FM), are reported in Table 1. In addition to the main outcomes, this table presents: (a) number of tested beams, (b) dimensions of the beams, (c) type of corrosion, and (d) corrosion levels if available. In this paper, the ductility of a structural element is expressed in the form of a ratio between the ultimate and yielding deflection. The studies are grouped in order to clearly distinguish the members subjected to different corrosion processes (natural or accelerated). Among them, four articles [29-32] dealt with the behavior of beams extracted by a decommissioned bridge (DB_N); three works [33-35] investigated the performance of beams with reduced dimensions with respect to the previous ones and subjected to a naturally corrosive environment (B_N); eleven papers [36-47] experimentally tested the flexural performance of PRC beams damaged by artificial corrosion (B_A). 
Table 1. Summary of the experimental studies on the effect of corrosion on pretensioned reinforced concrete (PRC) beams in flexure.

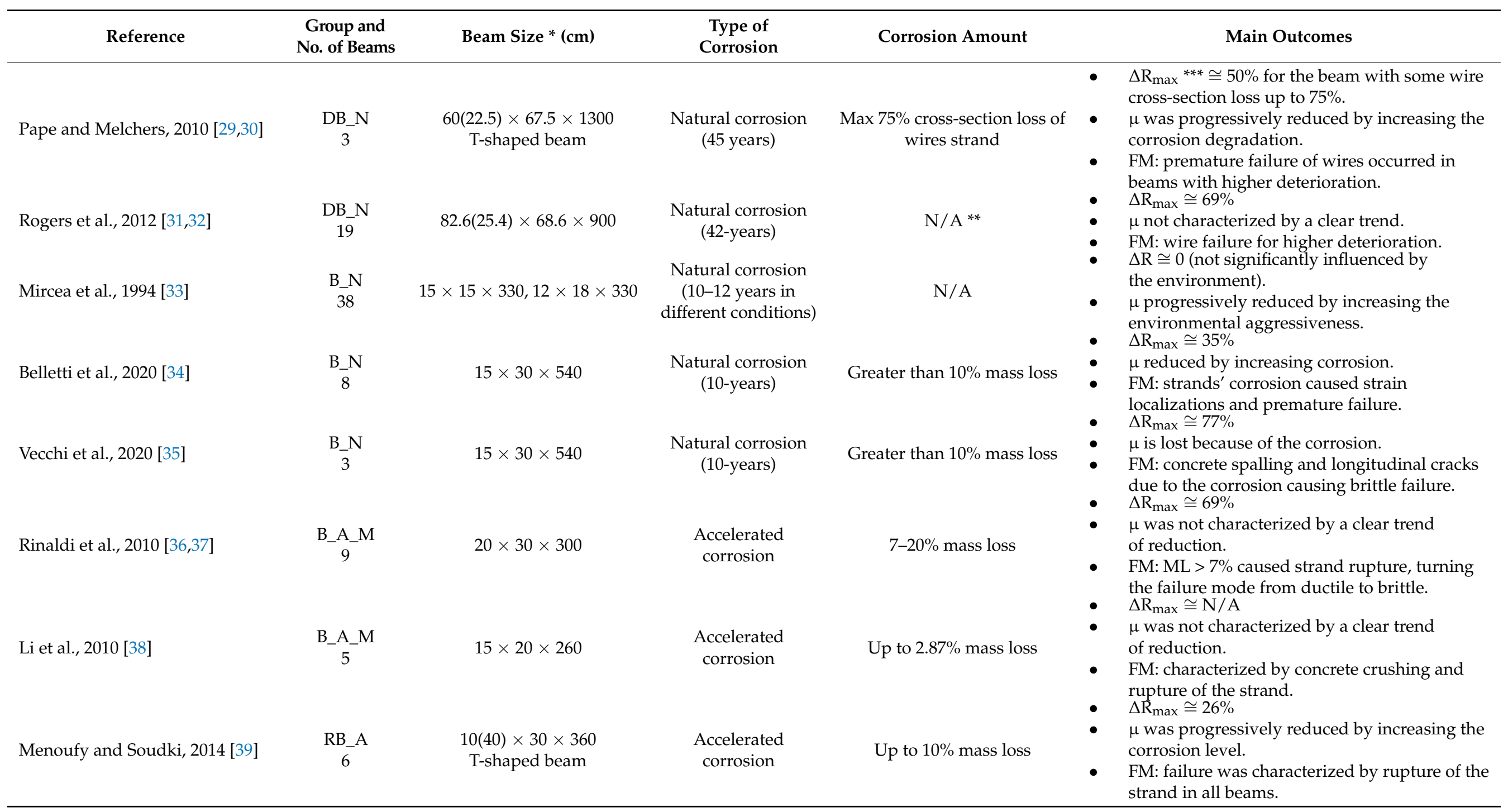


Table 1. Cont.

\begin{tabular}{|c|c|c|c|c|c|}
\hline Reference & $\begin{array}{l}\text { Group and } \\
\text { No. of Beams }\end{array}$ & Beam Size * $(\mathrm{cm})$ & $\begin{array}{l}\text { Type of } \\
\text { Corrosion }\end{array}$ & Corrosion Amount & Main Outcomes \\
\hline ElBatanouny et al., 2015 [40] & B_A_C & $\begin{array}{c}15.2(61) \times 38.1 \times 498 \\
\text { T-shaped beam }\end{array}$ & $\begin{array}{l}\text { Accelerated } \\
\text { corrosion }\end{array}$ & Up to $13 \%$ mass loss & $\begin{array}{ll}\text { - } & \Delta \mathrm{R}_{\max } \cong 33 \% \\
& \mu \text { was progressively reduced by increasing the } \\
& \text { corrosion level. } \\
\text { - } & \text { FM: characterized by concrete crushing and } \\
\text { significant deflection. } & \Delta \mathrm{R}_{\max } \cong 10 \%\end{array}$ \\
\hline Liu and Fan, 2019 [41] & $\begin{array}{c}\text { B_AR } \\
10\end{array}$ & $15 \times 25 \times 220$ & $\begin{array}{l}\text { Accelerated } \\
\text { corrosion }\end{array}$ & $\mathrm{N} / \mathrm{A}$ & $\begin{array}{l}\text { - } \mu \text { was progressively reduced by increasing the } \\
\text { corrosion degradation. } \\
\text { FM: corrosion turned the failure mode from } \\
\text { bending to shear. } \\
\text { - } \quad \Delta \mathrm{R}_{\max } \cong 60 \%\end{array}$ \\
\hline Yang et al., 2020 [42] & $\underset{6}{\text { B_A_M }}$ & $25 \times 45 \times 360$ & $\begin{array}{l}\text { Accelerated } \\
\text { corrosion }\end{array}$ & $30 \%$ mass loss on average & $\begin{array}{l}\text { - } \mu \text { was progressively reduced by increasing the } \\
\text { corrosion level. } \\
\text { - } \quad \Delta M: \text { brittle failure of strands. } \\
\Delta \mathrm{R}_{\max } \cong \mathrm{N} / \mathrm{A}\end{array}$ \\
\hline Dai et al., 2020 [43] & B_A_M & $13 \times 15 \times 200$ & $\begin{array}{l}\text { Accelerated } \\
\text { corrosion }\end{array}$ & Up to $14.7 \%$ mass loss & $\begin{array}{l}\text { - } \mu \text { was progressively reduced by increasing the } \\
\text { corrosion level. } \\
\text { - } \quad \mathrm{FM} \text { : concrete crushing. } \\
\Delta \mathrm{R}_{\max } \cong 4 \%\end{array}$ \\
\hline Benenato et al., 2020 [44] & $\underset{2}{\text { B_A_M }}$ & $20 \times 30 \times 300$ & $\begin{array}{l}\text { Accelerated } \\
\text { corrosion }\end{array}$ & $5.06 \%$ mass loss & $\begin{array}{l}\text { - } \quad \mu \text { was lost due to corrosion. } \\
\text { - } \quad \text { M: corrosion turned the failure mode from } \\
\text { ductile to brittle. } \\
\text { - } \Delta \mathrm{R}_{\max } \cong 17.3 \%\end{array}$ \\
\hline Liu et al., 2020 [45] & B_A_M & $15 \times 25 \times 220$ & $\begin{array}{l}\text { Accelerated } \\
\text { corrosion }\end{array}$ & Up to $10.2 \%$ mass loss & $\begin{array}{ll}\text { - } & \Delta \mu_{\max } \cong 19 \% \\
\text { - } & \text { FM: failure was characterized by concrete } \\
\text { - } & \text { FMushing and shear failure. } \\
\text { FMue fracture of corroded prestressing }\end{array}$ \\
\hline Zhang et al., 2016 [46] & $\begin{array}{c}\text { B_A_F } \\
13\end{array}$ & $15 \times 30 \times 270$ & $\begin{array}{l}\text { Accelerated } \\
\text { corrosion }\end{array}$ & Up to $5.6 \%$ mass loss & $\begin{array}{l}\text { wires caused the beam's failure. Higher } \\
\text { corrosion levels reduced the fatigue life of } \\
\text { the beam. }\end{array}$ \\
\hline Liu et al., 2019 [47] & B_A_F & $15 \times 30 \times 270$ & $\begin{array}{l}\text { Accelerated } \\
\text { corrosion }\end{array}$ & Up to $4 \%$ mass loss & $\begin{array}{l}\text { FM: the initial stiffness of corroded PRC beams } \\
\text { decreased after cyclic loadings and the brittle } \\
\text { failure was observed after corrosion degradation. }\end{array}$ \\
\hline
\end{tabular}

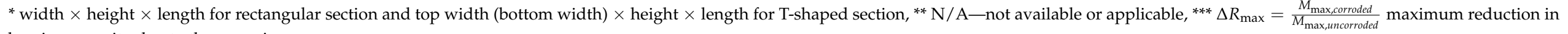
bearing capacity due to the corrosion. 
Concerning the artificially corroded PRC beams, nine papers [36-45] experimentally investigated the flexural performance decay under monotonic loads (B_A_M); with the aim of investigating the beneficial effects of retrofitting intervention by means of composite materials, two works $[39,41]$ also address the issue of the structural response of corroded PRC beams (RB_A); only one article [39] deals with both monotonic and cyclic flexure behavior (B_A_C); two papers $[46,47]$ investigate the fatigue performance of corroded PRC beams (B_A_F). In the following, the prominent key findings of this research are summarized with specific reference to the results obtained for the flexural performance of corroded beams. Wherever possible, the experimental results are collected, and the obtained load-displacement curves are directly compared in order to present a clear summary of the structural response after corrosion degradation.

\subsection{Naturally Corroded PRC Beams}

Papè and Melchers $[29,30]$ studied the behavior of three 45 year old bridge beams extracted from the Sorell Causeway bridge in Australia. The structure was $457 \mathrm{~m}$ long and consisted of 34 spans. As a reference element, a beam extracted from the same bridge, but in exceptionally good condition (only superficial rust was detected), was considered. One beam, declared to be in reasonable condition, was characterized by longitudinal cracks on both sides of the web and minimal rust staining; cross-sectional area losses on some of the wires averaged $57 \%$. The beam that was declared to be in poor condition presented severe longitudinal cracks on both sides of the web, minor spalling and minimal rust staining; cross-sectional area losses on some of the wires averaged $64 \%$. Concerning the prestressing strand corrosion, the reinforcement presented black spotting on the surface coupled with a corrosion pattern consistent with both general and pitting corrosion. Despite the accurate description of the suffered corrosion, the average mass loss evaluated on the entire strand was not declared.

From the beam tests, the authors observed that the corrosion of strands progressively reduced the flexural response of the PRC beam in terms of strength and ductility (Figure 1a). The observed reduction in the ultimate bending moment was $31 \%$ for the beam in reasonable condition and $49 \%$ for the beam in poor condition. Moreover, the number of wires broken during the flexural test seems strictly related to the increase in the load-bearing capacity reduction: 10 out of a total of 36 wires were fractured during the test in the case of the reference beam, 17 wires were fractured for the beam in reasonable condition, and 33 wires were fractured for the one in poor condition. The authors also showed the crack pattern of the beams after the flexural test. In the case of the reference beam, equally spaced cracks in the midspan can be observed, consistent with a flexural failure. In the corroded beams, however, large diagonal cracks that connected with the original longitudinal web cracking were formed. Therefore, variation in the collapse mode from flexural (ductile) failure to shear (brittle) failure was observed because of the corrosion degradation. The different failure modes of the reference and the corroded beams also emerged following the accurate analysis of the strands after the flexural testing: the failure surfaces of the prestressing wires were cup and cone-typical of ductile failure-in the reference beam (Figure 1b); in the corroded beams, the strands presented fracture surfaces in arrow-point form, typical of brittle failure (Figure 1c). 


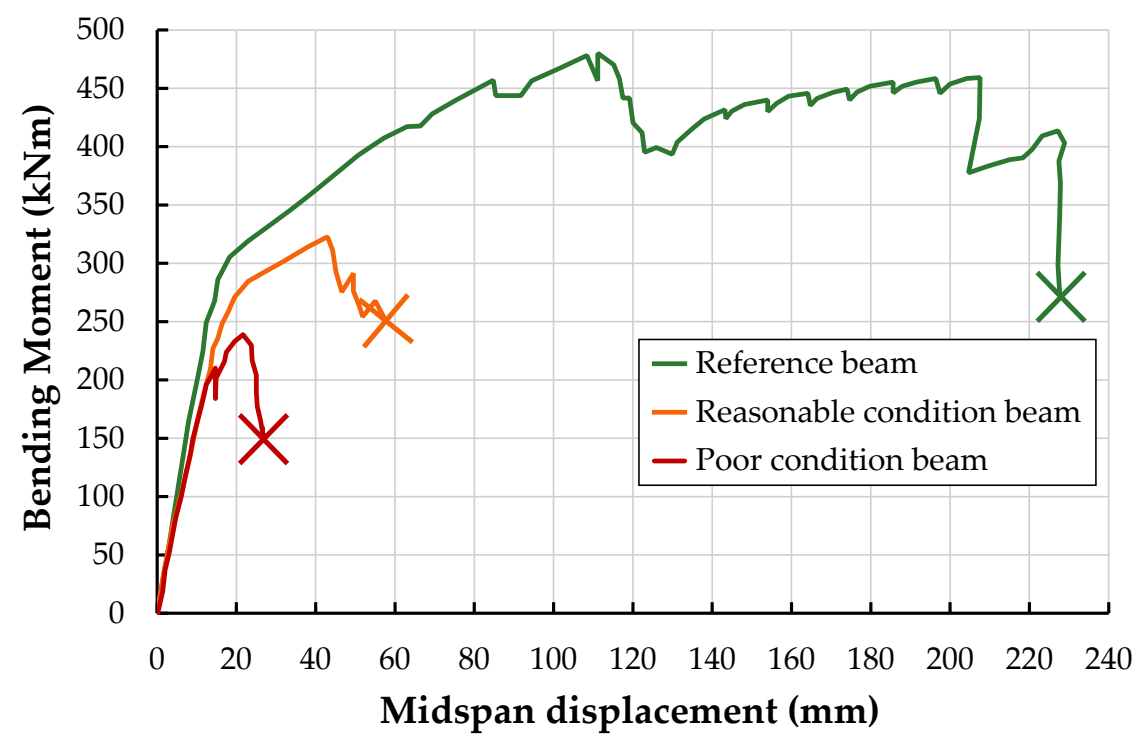

(a)

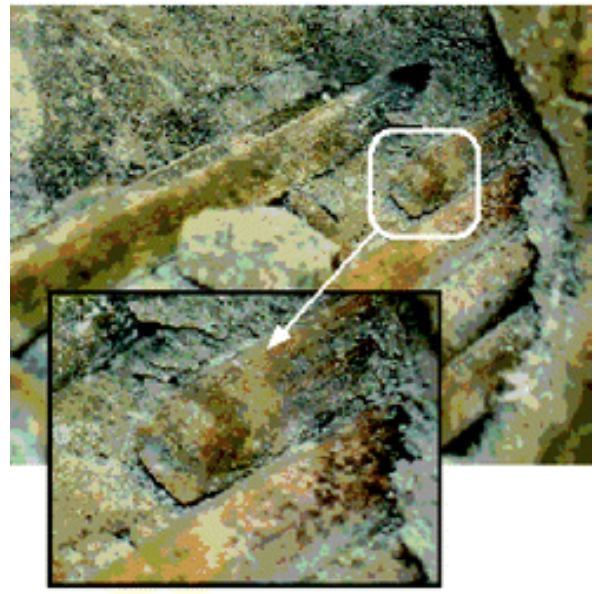

(b)

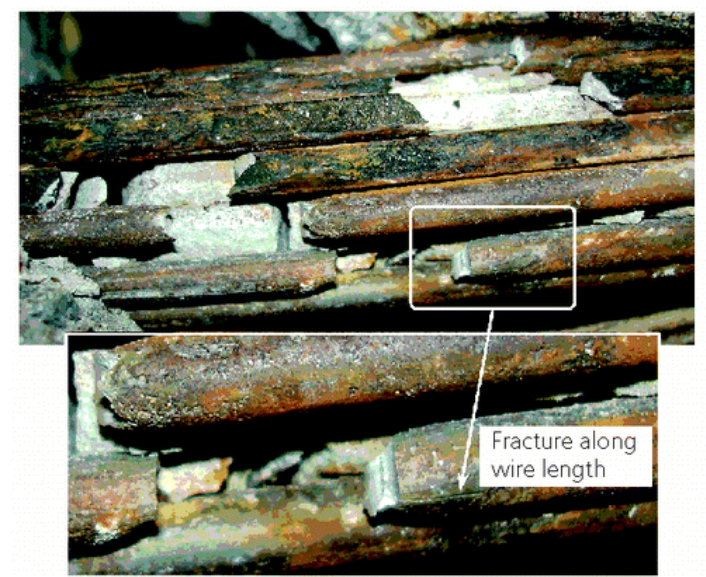

(c)

Figure 1. Experimental test by Pape and Melchers: (a) bending moment vs. midspan displacement curves, adapted from $[29,30],(\mathbf{b})$ ductile fracture of prestressing wires in the reference beam [30], and (c) brittle fracture of prestressing wires in the most corroded beam [30].

Rogers et al. [31,32], using four-point bending, tested 19 pretensioned beams extracted from the Tiwai Point, a decommissioned bridge in New Zealand consisting of 28 spans and a total length of $504 \mathrm{~m}$. After 42 years of exposition in an extremely aggressive coastal environment, the bridge showed a loss of up to $60 \%$ of the cross-section of the bottom layer of pretensioned strands. The surveys carried out indicated (i) average cover to strands of around $59 \mathrm{~mm}$, (ii) chloride content up to $0.3 \%$ by weight of concrete, and (iii) irrelevant carbonation depths. In the absence of longitudinal cracks or other corrosion signs-verified after testing-some beams were declared in good condition and considered as reference elements. For such members, the crack pattern at failure consisted of vertical flexural cracks spanning the middle third of the area. In some cases, a mixed shear-flexural failure also occurred, characterized by concrete crushing coupled with a flexural shear crack extending from one of the loading points. But, in the case of the corroded beams, only pure flexural failure was observed, with flexural cracks extending from the original corrosion crack. The strand failure was detected in samples with severe corrosion. Depending on both the reinforcement arrangement on the beams and the degree of corrosion, the reduction in the 
load-bearing capacity of the deteriorated beams is variable. The weakest corroded beams supported only $69 \%$ of their good-condition counterparts; unfortunately, the effective corrosion cross-section losses suffered by the tested beams were not assessed.

Mircea et al. [33] studied the behavior up to failure of reinforced and prestressed concrete beams subjected to a long-term natural degradation process under a constant load for a period ranging from 10 to 12 years. Four naturally aggressive environments were considered: urban environment, marine environment, chlorine pollution industrial environment and nitrogen pollution industrial environment. Moreover, reference specimens were preserved under laboratory conditions. It was reported that prestressed beams were characterized by a crack pattern (maximum width of 0.05 to $0.10 \mathrm{~mm}$ ) smaller than that observed for ordinary reinforced beams (maximum width of 0.15 to $0.20 \mathrm{~mm}$ ). Moreover, the beam tests performed after 10 to 12 years showed that the environmental condition did not significantly influence the beam's bearing capacity, i.e., only the nitrogen environment induced a $10-20 \%$ reduction in the ultimate moment after the corrosion. On the contrary, ductility decay depending on the environmental aggressiveness was observed in all cases. No data of the attained corrosion level were indicated.

Belletti et al. [34] carried out an experimental campaign on full-scale PRC beams extracted from the refrigeration tower of a thermal power plant. During their lifecycle, the beams were subjected to refrigerating wetting cycles with marine water for 10 years. An initial prestressing action of $1408 \mathrm{MPa}$ was declared, which was approximately 0.89 times the nominal yield strength of the strands $\left(f_{\mathrm{p} 0.1 \mathrm{k}}=1580 \mathrm{MPa}\right)$. Corrosion caused longitudinal cracks, swelling, splitting phenomena and spalling of concrete cover. According to the authors of [34], the mass loss suffered by the prestressing tendons varied along each beam. To carefully report the corrosion distribution along the beams, the authors subdivided the tendons into different segments to classify them on the basis of the corrosion level (CL) observed. Three ranges of values pertaining to the measured mass loss were observed: a low corrosion level $(<2 \%)$, a medium corrosion level $(2-10 \%)$ and a high corrosion level $(>10 \%)$. For the sake of clarity, a diagram of the corrosion level distribution along the tested beams presented in [34] is provided in Figure 2a. Each beam is characterized by a combination of two or three corrosion levels; therefore, each element is subjected to a different deterioration distribution. To gain insight into the influence of the degradation on the flexural behavior of the corroded beams, for each beam, the average corrosion level was calculated considering the different corrosion levels of the segments in between the supports. Moreover, according to the information given in [49], 20\% mass loss was assumed in the case of the higher corrosion level. Therefore, the weighted mean was calculated and the average CL assigned to each beam was estimated as the mean value of the mass loss evaluated for each prestressing reinforcement.

Since the existing beams were damaged in the inferior part, the authors decided to perform experimental four-point tests adopting different span lengths for each beam depending on the extension of concrete cover spalling caused by the corrosion at the beam-ends [34]. The positions of the supports are depicted in Figure 2a with the span lengths $L$ used for each beam. In detail, the span length varied from $5.04 \mathrm{~m}$ (in the case of the reference beam) to $3.11 \mathrm{~m}$ (for the PB4P14 specimen characterized by an average corrosion level of approximately $6.03 \%$ ). In order to make the results comparable for the different beams, at least in terms of loading, in the present paper, the load-displacement curves provided by the authors were transformed in the bending moment-displacement curves (see Figure $2 b$ ) to provide a clearer overall view of the experimental findings. It is worth noting that the midspan deflections are not comparable, since they are influenced by the different span lengths. 


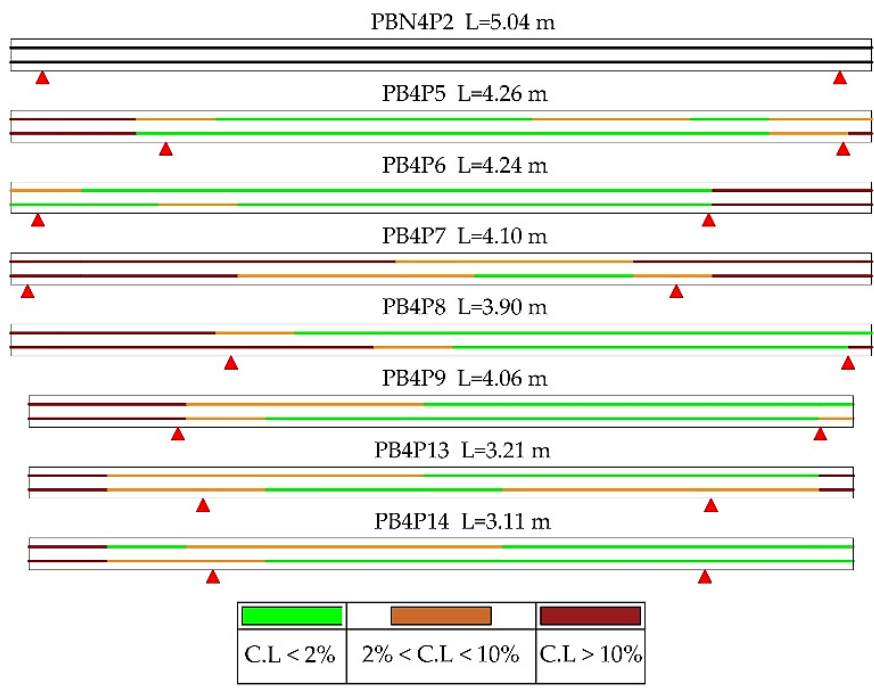

(a)

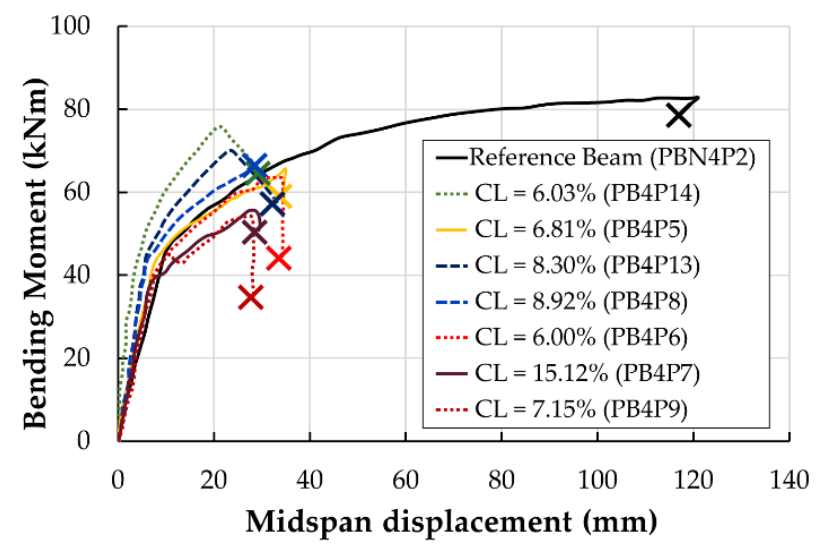

(b)

Figure 2. Experimental test by Belletti et al. [34]: (a) corrosion level (CL) distribution along the tested beams, and (b) bending moment vs. midspan displacement curves adapted from [34].

The analysis of the experimental results clearly shows that the corrosion deterioration progressively reduces the beams' ductility and strength. After ruling out some exceptions, a trend in the reduction of the flexural strength depending on the corrosion level can be observed. Concerning the beam referred to as PB4P9 in [34] and characterized by an average corrosion level of $7.15 \%$, a lower structural response can be observed. However, such a result can be completely disregarded since the beam is characterized by a premature pure shear collapse, as highlighted by the authors, analyzing the crack pattern in the deformation maps captured by digital image correlation (DIC) during both the test and the collapse. The structural performance of the beams referred to as PB4P5 and PB4P6 in [34] does not appear to be consistent with the rest of the experimental campaign. In this case, however, the reason does not lie in the variation in the failure mode but rather in the value attributed to the assigned corrosion level. In fact, even if low to mid-corrosion can be observed between the supports, the structural response could be governed by the presence of deeper pits along the strands. In fact, the pitting corrosion provides stress localization, causing the wires to rupture and, therefore, resulting in the brittle failure of the beam. It is worth noting that the presence of localized pits along the strands is a significant uncertainty parameter that could not substantially modify the mass loss of a certain section. Therefore, the average mass loss should be regarded only as an index of the possible structural behavior, which must be ever associated with the dimension and the location of the deeper pits. Unfortunately, the maximum pit depth and location have not been indicated in either case in [34].

From the same existing structure, another three beams were extracted and the experimental results are presented in Vecchi et al. [35]. Concerning the behavior of the corroded prestressed beams described in [35], a reduction in ultimate bending moment and ductility was found. According to the authors, the decay was approximately $17.39 \%$ and $77.35 \%$ for average corrosion levels of $5.7 \%$ and $9.3 \%$, respectively. The latter was estimated according to the information given in [49], since only an average corrosion level on $500 \mathrm{~mm}$ long prestressing strand pieces was provided in [35]. The most corroded beam presented an extended region with a high level of corrosion in the midspan, coupled with longitudinal cracks, splitting phenomena and concrete cover spalling. According to the authors, the brittle flexural behavior of this beam can be related to a combination of factors (localized high level of corrosion, splitting phenomena caused by corrosion of strands, bond deterioration with large strand slip, concrete crushing and spalling), which makes the interpretation of the corroded beam performance problematic. On the contrary, the other corroded beam 
did not show longitudinal cracks or concrete spalling due to the degradation, showing a crack pattern during the collapse characterized by multiple vertical cracks at the midspan coupled with low ductility. It is noteworthy that this beam exhibited strand rupture at failure, contrary to what was observed for the more highly corroded specimen.

\subsection{Artificially Corroded PRC Beams}

Rinaldi et al. [36,37] conducted experimental testing on corroded and uncorroded PRC beams with four-point bending. The strands were prestressed to $1300 \mathrm{MPa}$, which was approximately 0.70 times of their nominal ultimate strength. In total, nine PRC beamscharacterized by different concrete compressive strengths (34.0, 41.5 and $47.4 \mathrm{MPa}$ )—were artificially corroded, with various percentages of mass loss $(7 \%, 14 \%$ and $20 \%$ by loss of steel mass of each strand); in all cases, the corrosion was restricted to the bending zone of the beams. The obtained results are represented in Figure 3a in the form of bending moment-displacement curves. In the concrete with $34.0 \mathrm{MPa}$ compressive strength, the bearing-capacity loss was between $28 \%$ and $41 \%$ under severe corrosion ( $20 \%$ by mass loss). However, in the good-quality concrete, corrosion of medium and severe corrosion levels $(14 \%$ and $20 \%$ ) led to a sharp reduction in the capacity (up to $66 \%$ ). Moreover, ductility degradation, due to the increase in the corrosion level, can be observed in the results. The analysis of the crack pattern resulting from the collapse suffered by the beams (Figure $3 b$ ) indicates that corrosion changes the failure mechanism of PRC beams. With the exception of the beam characterized by higher concrete strength - for which pure bending failure was observed-in the absence of corrosion, collapses occurred for concrete crushing accompanied by bending and shear interaction. The crack pattern at failure becomes more localized with an increased corrosion level. In detail, for the beam with 7\% mass loss, vertical cracks between the two-point loads and inclined cracks in the shear spans can be observed, whereas for the higher corrosion levels, the crack pattern is characterized only by sub-vertical cracks with branches. With the exception of the lower corrosion level-for which the simultaneous crisis in concrete and strands occurred-the strand failure governed the collapse of the corroded beams. Since, during the test, the sudden rupture of the prestressing wires weakened by the corrosion deterioration was observed, the structural performance of the corroded beams is associated with the average level of corrosion achieved. Nevertheless, it can be assumed that the stress and strain localization provided by the pitting corrosion is the cause of the wire rupture. Therefore, it is concluded that the mass loss can be considered only as an index of the severity of degradation, since the beams' ultimate capacity is governed by the stress localization in the corrosion pit. For a better explanation, a picture of the strand is presented in Figure 4 for the case of specimen B8 (characterized by a $20 \%$ mass loss and a concrete strength of $34.0 \mathrm{MPa}$ ). Specimen B8 collapsed due to the wire strands' local rupture in the section affected by the deeper corrosion pit; see Figure $4 b$.

Li and Yuan [38] experimentally investigated the performance of ten PRC beams, of which five were pretensioned RC beams and five were post-tensioned ones. The beams were characterized by the same materials and reinforcement arrangements. An initial prestressing action of $1395 \mathrm{MPa}$, which is approximately 0.75 times the strands' characteristic ultimate strength $\left(f_{p t k}=1860 \mathrm{MPa}\right)$, was applied to the beams. The corrosion was induced by means of an electrolytic procedure, where the degradation process was catalyzed by introducing 3\% sodium chloride into the mass fraction of cement. With reference to the PRC beams, the obtained corrosion degree was extremely low, up to $2.87 \%$ in mass loss. To evaluate the flexural capacity of the corroded beams, four-point bending tests were performed. In any case, it is important to note that the result regarding the reference uncorroded beam cannot be employed since this member prematurely collapsed in pure shear coupled with the slippage of the steel strand. It seems that the pretensioned system was inefficient and, at the peak load, the prestressing action was completely lost since the maximum strength of the uncorroded specimen matched the ultimate bending moment of the beam characterized only by mild reinforcement. A synthesis of the results of the ex- 
perimental campaign is presented in Figure 5a, where the bending moment-displacement curves are provided.

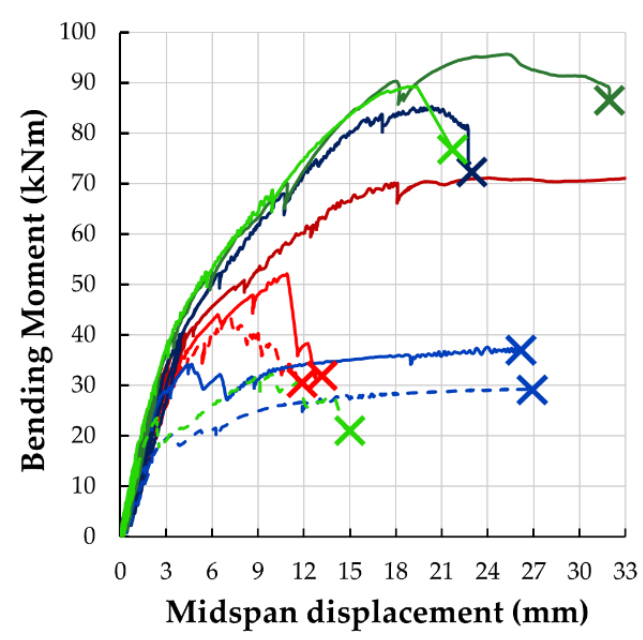

\begin{tabular}{|l|}
\hline Series I - Rc=34 MPa \\
- Reference Beam (B7) \\
- CL $=20 \%(B 9)$ \\
- - CL $=20 \%(B 8)$ \\
\hline Series II - Rc=41.5 MPa \\
- Reference Beam (B2) \\
- CL $=14 \%$ (B3) \\
- - CL $=20 \%$ (B1) \\
\hline Series III - Rc $=47.4 \mathrm{MPa}$ \\
- Reference Beam (B4) \\
- CL $=7 \%(B 6)$ \\
- - CL $=20 \%(B 5)$
\end{tabular}

(a)

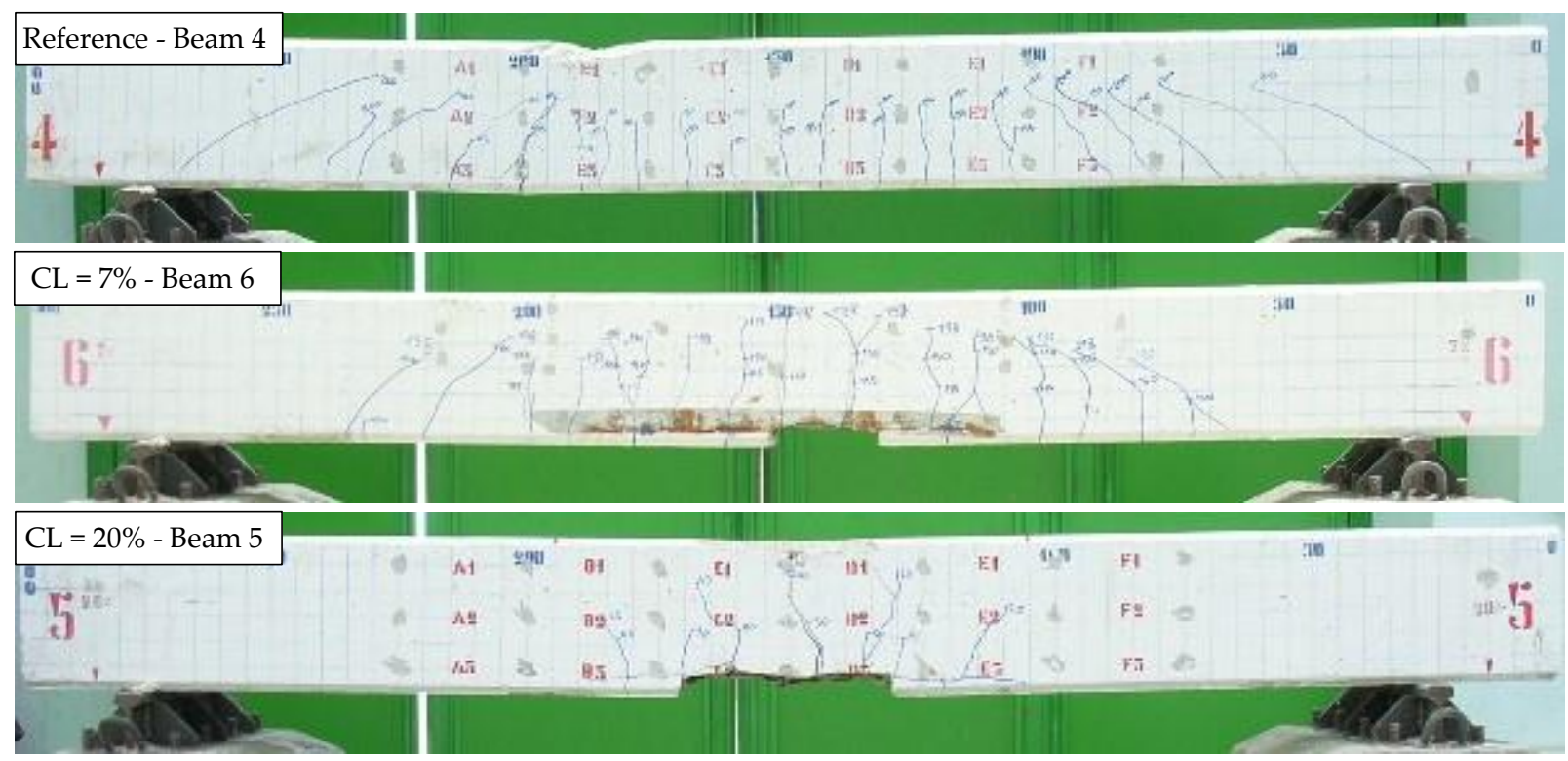

(b)

Figure 3. Experimental tests by Rinaldi et al. [37]: (a) bending moment vs. midspan displacement curves at different corrosion levels (CL), adapted from [37], and (b) crack pattern during the collapse of the corroded and uncorroded beams [37].

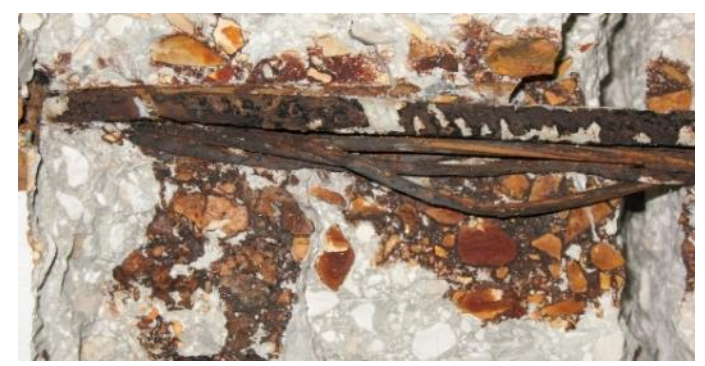

(a)

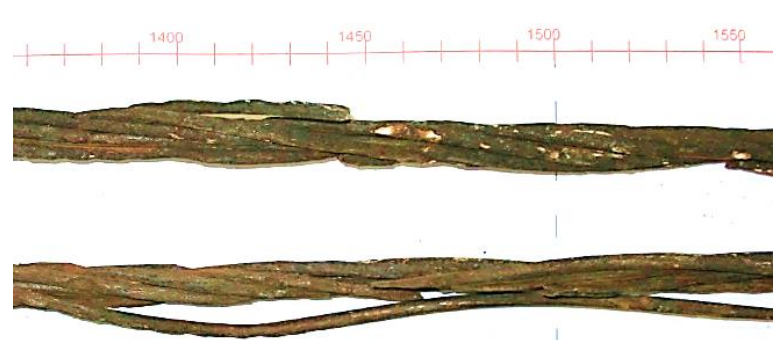

(b)

Figure 4. Experimental tests by Rinaldi et al. [36]: (a) prestressing strand failure in corroded beam 8 (20\% mass loss), and (b) examples of strand corrosion in specimen B8. 


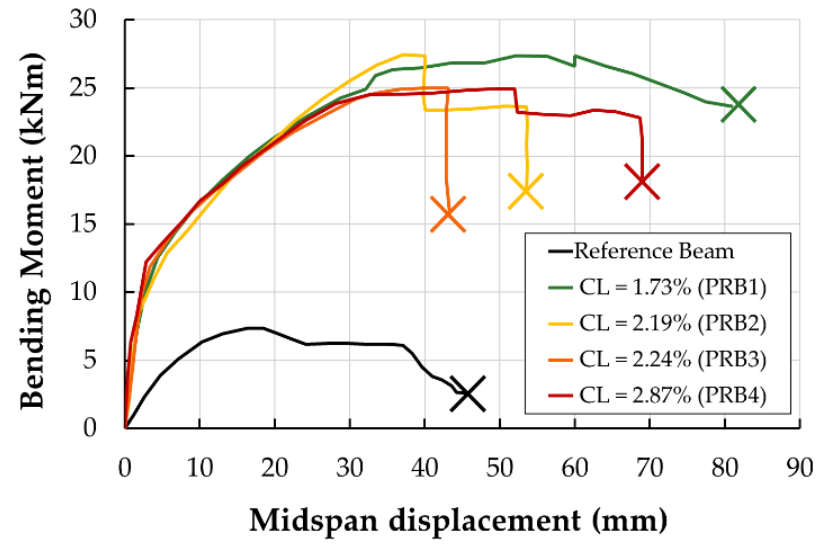

(a)

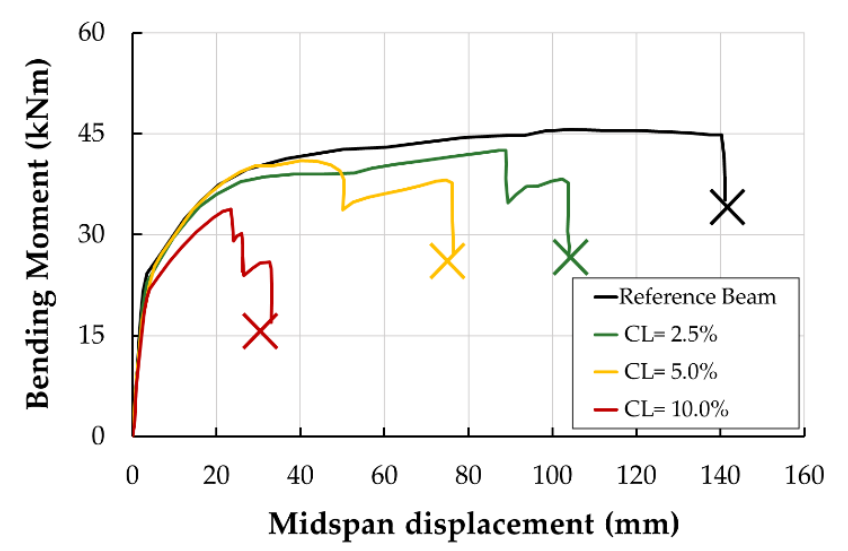

(b)

Figure 5. Bending moment vs. midspan displacement curves at different corrosion levels (CL), adapted from: (a) experimental test results by Li and Yuan [38], and (b) experimental test results by Menoufy and Soudki [39].

Due to the erroneous behavior of the reference beam, the evaluation of the reduction in bending capacity due to corrosion is not possible. However, according to the experimental results of the corroded beams, a slight reduction in the ultimate load due to the increased level of corrosion was observed, accompanied by a ductility variation trend that did not appear to be well-defined, probably since the level of corrosion was similar for the analyzed beams.

Menoufy and Soudki [39] assessed the effect of corrosion of strands on the residual capacity of PRC T-beams. To this aim, six full-scale PRC T-shaped beams were tested with four-point bending. The prestressing strands were tensioned to $70 \%$ of their ultimate stress. In this study, only the central tension region of the beams ( $1 \mathrm{~m}$ in length) was corroded. It is worth underlining that the specimens were characterized by only one strand in tension; therefore, the flexural performance of the beam was strictly related to the tensile behavior of the corroded strand. In fact, in all the corroded specimens, the failure occurred due to rupturing of the tendons. All the beam specimens were subjected to accelerated corrosion to achieve $2.5 \%, 5 \%$ and $10 \%$ mass loss. A synthesis of the results of the experimental campaign is reported in Figure 5b, where the bending moment-displacement curves are represented. Corrosion reduced the flexural capacity of the PRC beams: for $2.5 \%$ and $5 \%$ mass losses, the reductions in ultimate load capacity were $6.5 \%$ and $9 \%$, respectively; for $10 \%$ mass loss, the reduced ultimate capacity was $26 \%$, and up to $76 \%$ reduction in midspan deflection was measured.

ElBatanouny et al. [40] tested eight prestressed T-shaped RC beams under cyclic loading. The experimental campaign consisted of two sets of beams, identical in prestressing force and design but characterized by different concrete strengths (29.0 and 40.7 MPa) and accelerated corrosion techniques (impressed current and wet/dry cycles). The strands were prestressed to $1265 \mathrm{MPa}$, which is approximately 0.68 times their nominal ultimate strength $\left(\mathrm{f}_{\mathrm{pu}}=1860 \mathrm{MPa}\right)$. The first set of tested members was composed of two beams, characterized by strands that were slightly corroded before the concrete casting ( $4 \%$ uniform mass loss). In this group, one beam was considered as a reference, while the other one was preloaded in four points to $80 \%$ of the nominal capacity and exposed to a chloride solution using a 3-day wet/4-day dry cycle to accelerate corrosion. The attained corrosion level was $4.9 \%$ mass loss. 
The second set of beams consisted of two reference beams and four beams preloaded to $60 \%$ of the nominal capacity and electrolytically corroded to achieve mass losses between $6.3 \%$ and $12.8 \%$. Both monotonic and cyclic load tests were conducted on the beams. Depending on the adopted accelerated corrosion techniques, different structural responses could be observed: in the first set, the structural response seemed to be most deeply marked by the corrosion degradation, compared to the beams of the second group. Probably, this peculiar behavior can be explained by considering the fact that the effects of the artificial corrosion process are related to the crack width obtained during the preload phase: in the first set, the beams were preloaded to achieve a crack of $0.8 \mathrm{~mm}$, while in the second group, the target crack width was $0.4 \mathrm{~mm}$. This means that the corroded beam of the first set should have been characterized by localized pits of a greater extent and lower depth with respect to those formed in the second set under the same corrosion level. Unfortunately, the dimensions of the localized pits formed on the tested beams are not indicated in [40]. Concerning the monotonic tests on the second group of beams, a reduction in the load-bearing capacity and deflection of the PRC beams were observed after increasing the corrosion level. The reduction in the ultimate load capacity varied between $11 \%$ and $32.8 \%$, while the maximum deflection was reduced in the range of $12.5-32.4 \%$. In the cyclic tests, corrosion due to the deviation from linearity significantly reduced the maximum load achieved during the test and increased the reinforcement slippage as well as the crack opening or widening.

Yang et al. [42], unlike other experimental groups, performed the artificial corrosion of PRC beams during the application of a high bending moment. In total, six beam specimens were fabricated and corroded using an accelerated corrosion procedure. An initial prestressing action of $1398 \mathrm{MPa}$ was applied, which is 0.75 times the steel strands with a nominal ultimate strength $\left(\mathrm{f}_{\mathrm{ptk}}=1860 \mathrm{MPa}\right)$. Simultaneously, the beams were subjected to wet/dry cycles using direct current (DC) power, i.e., the specimens were kept for 3 and 4 days in dry and wet conditions, respectively. They used a sponge containing $5 \%$ sodium chloride solution to corrode the beams. The corrosion level attained was, on average, $30 \%$ in mass loss. During the artificial corrosion process, the specimens were subjected to a sustained load $(0,50$ and $100 \mathrm{kN})$, in a four-point bending configuration. It should be noted that 50 and $100 \mathrm{kN}$ represent around $30 \%$ and $60 \%$ of the designed ultimate bearing capacity of the beams, respectively. The entire process of loading and corrosion took 550 days. Subsequently, the specimens were monotonically loaded under a bending test machine up to $500 \mathrm{kN}$. The experimental results are synthesized in terms of bending moment-displacement curves (Figure 6a). None of the uncorroded beams experienced collapse, contrary to what was observed for the corroded specimens, which collapsed due to the rupture of the strands. The combined application of sustained load and corrosion resulted in a larger total loss of prestressing force than the case subjected to corrosion without sustained loads. In Yang et al. [42], the time-dependent tendon force was measured by means of a nondestructive technique based on sensors measuring the magnetic permeability of prestressed tendons. The largest total loss of prestressing force was around $56 \%$ for a beam subjected to $60 \%$ of its designed ultimate load during the corrosion process. Moreover, it was shown that prestressing force can restrict the development of transverse cracks during severe corrosion in the strands. Yang et al. [42] also found that a sustained load promotes corrosion localization, and beam specimens subjected to higher loads displayed more severe pitting corrosion. Other researchers report the importance of pitting corrosion in the failure of RC beams as well [50-53]. In fact, pitting corrosion dramatically reduces the mechanical properties of strands. 


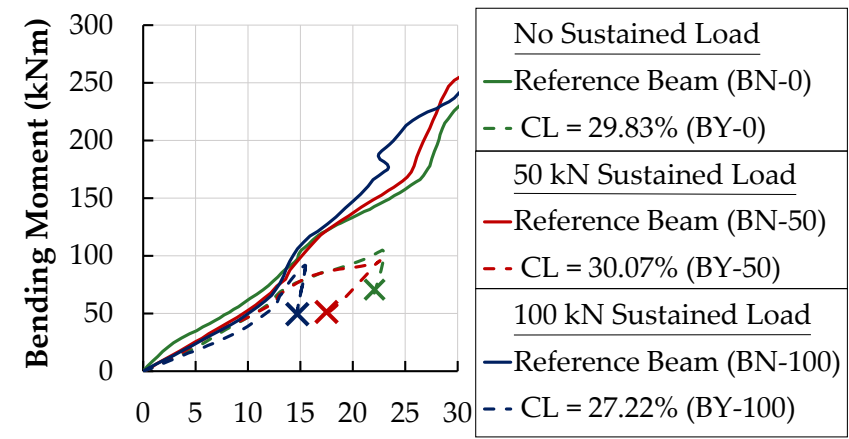

Midspan displacement (mm)

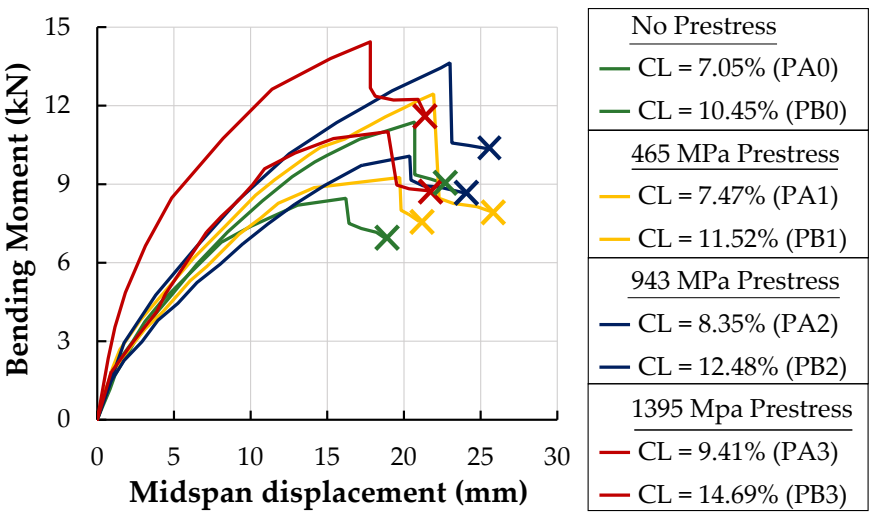

(b)

Figure 6. Bending moment vs. midspan displacement curves at different corrosion levels (CL), adapted from: (a) experimental test results by Yang et al. [42], and (b) experimental test results by Dai et al. [43].

Dai et al. [43] investigated the effect of the level of prestress load on the corrosion level and consequently on the reduction of flexural capacity. With this aim, they performed a four-point flexural test on eight PRC corroded beams characterized by corrosion levels between $7.05 \%$ and $14.96 \%$ and different levels of prestressing action (from 0 to $1395 \mathrm{MPa}$; the yield and ultimate strengths of the strand were 1830 and $1910 \mathrm{MPa}$, respectively). The electrochemical method was employed to accelerate the strand corrosion, by applying a constant current of $0.1 \mathrm{~A}$ in the inferior strands for 15 (PA series) or 20 days (PB series). The beams were partially submerged in a corrosion tank. According to the authors of [43], high strand stresses can accelerate the corrosion-induced prestress loss, e.g., by varying the strand stress level from $25 \%$ to $75 \%$ of the tendon strength, the corrosion-induced prestress loss increases by $20 \%$. In Figure $6 \mathrm{~b}$, the obtained bending moment-deflection curves are presented. After varying the prestressing action, beams subjected to 15 days of artificial corrosion showed mass losses between $7.47 \%$ and $9.41 \%$ coupled with prestress losses of $12.0 \%$ up to $31.3 \%$. After increasing the corrosion duration, prestress losses from $34.4 \%$ up to $55.3 \%$ were measured, coupled with corrosion levels of $11.52 \%$ and $14.69 \%$, respectively. Even if this study is significant because it is the only one in which the prestress losses are measured, it should be mentioned that the results of the reference uncorroded beams are omitted; thus, no consideration is given to the flexural strength and ductility reduction due to the corrosion.

Benenato et al. [44] conducted experimental testing on two PRC beams using fourpoint bending, characterized by an initial prestressing action of $1300 \mathrm{MPa}$, approximately 0.70 times the nominal ultimate strength of the prestressing tendons. The work is part of a research project aiming to parse out the impact of a low degree of corrosion on the structural behavior of PRC beams. One beam was considered as a reference, while the other was subjected to an artificial corrosion process designed to produce realistic deterioration (the corrosion spreads along the entire structural element but is more marked on the shear spans), with an attained corrosion level at an average of $5.06 \%$ in mass loss. This corrosion level causes a loss of ductility, while the strength is practically unchanged (Figure 7a). The behavior of the corroded beam was similar to that of the reference beam up to the peak load. Concerning the brittle failure of the corroded beam, the collapse can be attributed to the concurrent concrete crushing and tendon failure, associated with a very sudden softening branch. As highlighted by the crack patterns (Figure 7b), the sound beam shows vertical cracks between the two load points and inclined cracks close to the supports. Moreover, during the collapse, concrete crushing combined with the bucking of the compressed reinforcement occurs. On the contrary, in the corroded beam, only slight concrete crushing is manifested, while inclined cracks form only near the load points. 


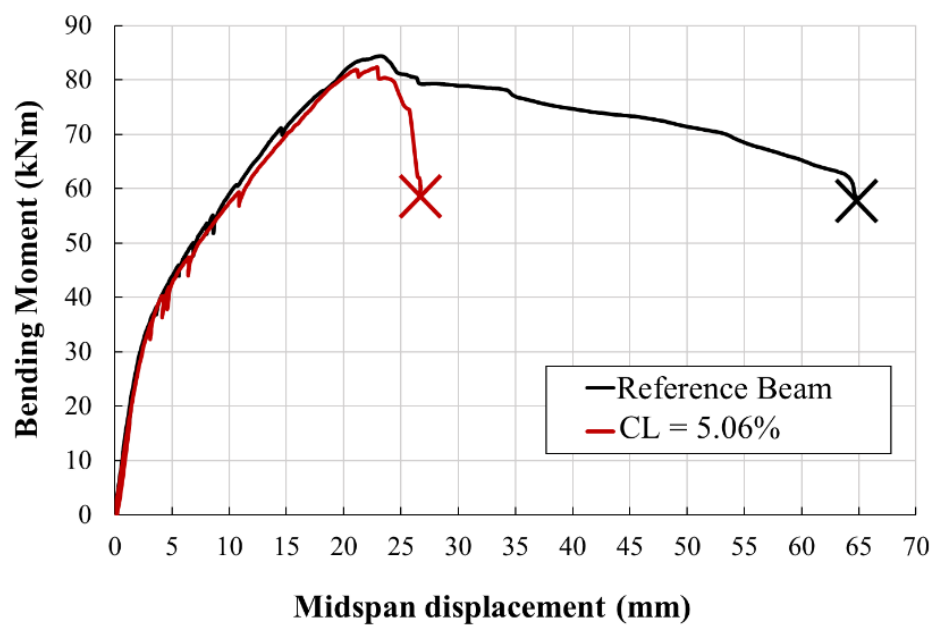

(a)
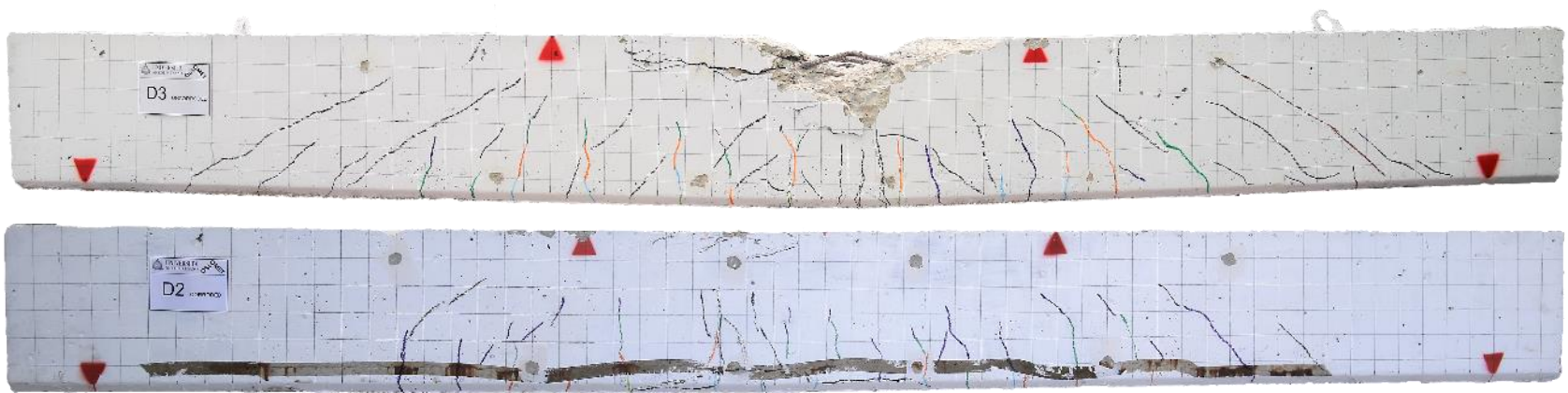

(b)

Figure 7. Experimental test by Benenato et al. [44]: (a) bending moment-deflection curves at different corrosion levels (CL), adapted from [44], and (b) crack pattern after the collapse of the corroded and uncorroded beams.

In Figure 8, an example of strand corrosion and their local rupture that occurs during flexural testing is presented. Wire failure was identified along the strand where the wire's cross-section, because of the formation of localized pits, was reduced and became insufficient to sustain the superimposed stress state. Since the failure of a corroded wire is the consequence of a crack originating in a corrosion pit, it makes sense that the shape of the pitting affects the fracture surfaces of the prestressing wires. Therefore, we can find arrow-point type fracture surfaces (Figure 8 b) or inclined shapes with valley breaks (Figure 8c) -in all cases, shapes which are typical of the brittle failure of steel wire.

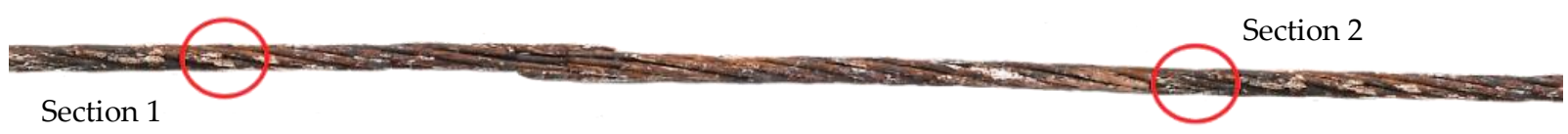

(a)

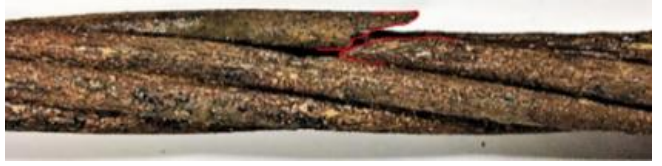

(b)

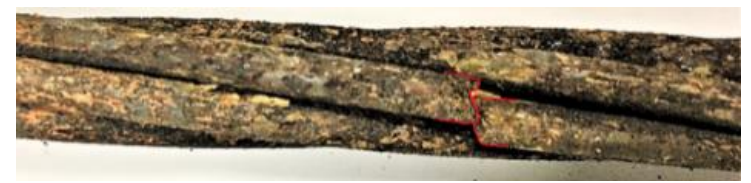

(c)

Figure 8. Experimental test by Benenato et al. [44]: (a) corroded strand extracted from the beam, (b) example of arrow-point type fracture (Section 1 in Figure 8a), and (c) example of inclined-shape fracture (Section 2 in Figure 8a). 
Since the beams tested by Benenato et al. [44] have the same geometry and reinforcement as the specimen tested in [36,37], the experimental results can be directly compared. The collapse mode of the corroded beams is similar for the two experimental campaigns: (i) a maximum load close to that of the reference beam, (ii) an abrupt failure, and (iii) a collapse occurring due to the simultaneous occurrence of concrete crushing and wire rupture in the strands. Hence, the existence of a transition stage between the two phases of the flexural performance of corroded PRC beams can be confirmed, the first characterized by low corrosion levels associated with a progressive ductility reduction without bearing-capacity losses and the second characterized by high corrosion levels coupled with a flexural strength reduction and a failure mechanism modification, as already observed by other authors $[28,36,37]$.

Liu et al. [45] conducted experimental testing on five PRC beams using four-point bending. A very low initial prestressing action of $558 \mathrm{MPa}$, only 0.30 times the nominal strand yield strength, was applied. The beams were subjected to accelerated corrosion for up to 42 days by means of the electrochemical method. A synthesis of the experimental results is presented in Figure 9a, where bending moment-displacement curves are provided. It is shown that slight corrosion has a weak effect on the flexural behavior of prestressed concrete beams, even if a reduction in the strand slip is observed to increase the corrosion level. Therefore, in the experimental work by Liu et al. [45], a variation in the strand-toconcrete interaction due to the corrosion was detected. The flexural capacity decreases for corrosion levels higher than $7 \%$. For a corrosion level of $10.2 \%$, the ultimate deflection decreases by $18.7 \%$, the flexural capacity reduction is $17.3 \%$, and the ductility declines by $19 \%$. However, the slip between the corroded steel strand and concrete increases: the ultimate slip rises from 5 to $11.4 \mu \mathrm{m}$.

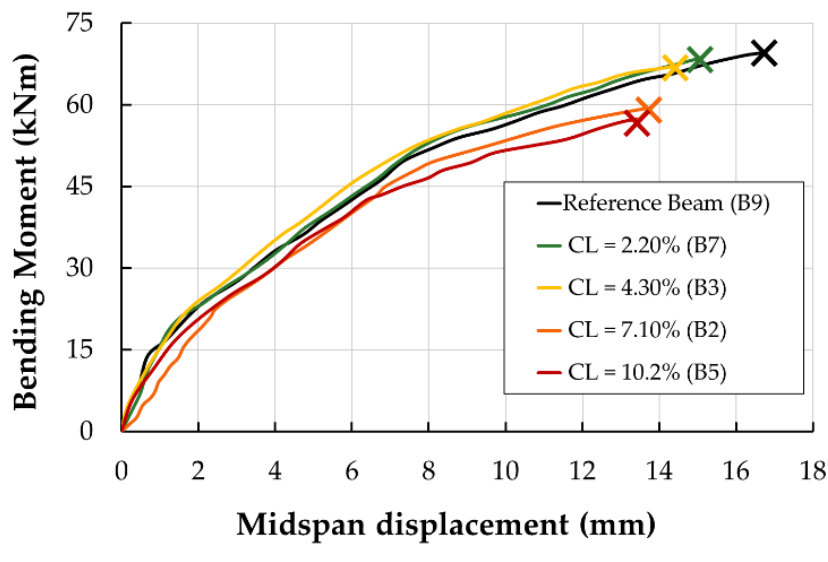

(a)

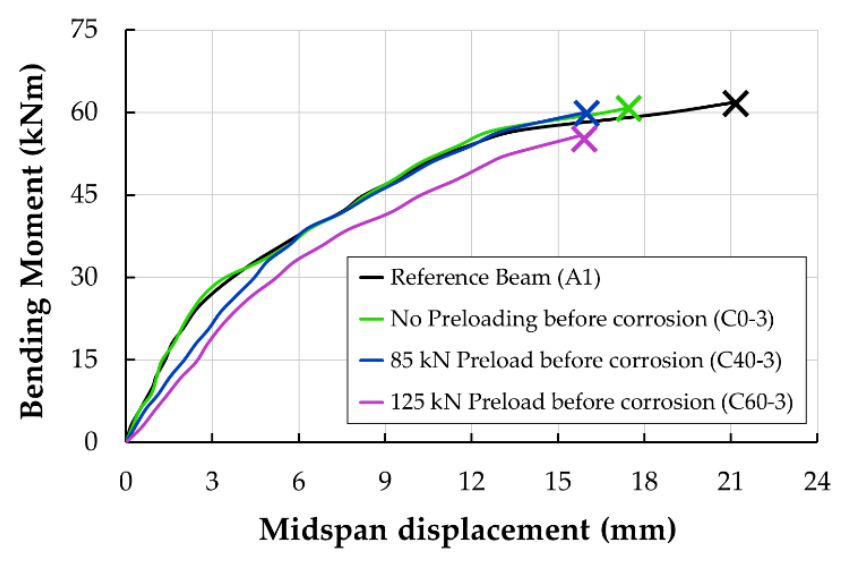

(b)

Figure 9. Bending moment vs. midspan displacement curves at different corrosion levels (CL), adapted from: (a) experimental test results by Liu et al. [45] and (b) experimental test results by Liu and Fan [41].

To address the behavior of corroded beams retrofitted with composite materials, Liu and Fan [41] studied the effects of initial damages and chloride corrosion on the flexural behavior of prestressed concrete beams. In the following, the performance of the non-retrofitted beams is analyzed. Therefore, only the results obtained for four prestressed concrete beams, which were preloaded with $0 \%, 40 \%$ and $60 \%$ of the ultimate load, are presented. In addition, in this case, 30\% of the strands' yield stress was the initial prestressing amount. The beams were immersed in chloride solution $\left(\mathrm{CaCl}_{2}\right.$ and $\mathrm{MgCl}_{2}$ with $5 \%$ concentration) for 120 days. Unfortunately, the attained corrosion level is not reported in the paper. Four-point bending tests were performed. The sectional strain, deformation, flexural stiffness, flexural capacity, ductility and cracking characteristics were reported but they were not correlated with the observed corrosion level. Figure $9 \mathrm{~b}$ presents a synthesis of the experimental results in the form of a bending moment-displacement 
curve. In general, it can be observed that corrosion reduced the ductility by up to $21 \%$ and the flexural capacity by up to $10 \%$.

Zhang et al. [46] tested thirteen pretensioned, partially prestressed concrete beams under cyclic loading. The prestressing reinforcements were pretensioned up to $75 \%$ of their nominal ultimate tensile strength. The beams were artificially corroded up to $5.6 \%$ average mass loss. It was reported that all the beams failed at the location of the maximum cross-section loss. The localized cross-sectional losses of the specimens were ten times greater than the average cross-section loss. The fracturing of the first wire in three corroded beams characterized by mass losses of $1.3 \%, 2.5 \%$ and $5.6 \%$ occurred at approximately $421,000,219,000$ and 166,000 cycles, respectively. Compared with the uncorroded beam, the fatigue life of the three corroded beams displayed a reduction of $44 \%, 80 \%$ and $83 \%$, respectively. Unfortunately, no load-deflection curves are reported in the paper. However, the analysis of the fatigue fracture surface in the beam characterized by a $2.5 \%$ average cross-section loss crack pattern (Figure 10) is interesting. To do this, the authors [46] employed a scanning electron microscope (SEM) to analyze the surface of the fractured wire. In the high-magnification image, the crack origins around the pit, where many voids and interconnected cracks are present—-triggered by the fatigue failure-can be observed. The propagation zone shows a flat surface with fine, randomly dispersed and isolated cracks caused by the loading cycles. More recently, the same authors (Liu et al. [54]) extracted from the failed beams a huge amount of corroded prestressing wire pieces, with the aim of probabilistical assessing the stress state developed around the corrosion pit during the fatigue test. To achieve this goal, the morphology of the corroded prestressing wires was studied by reconstructing 3D geometric models (acquired by means of a highresolution laser scanner). Moreover, the stress state around each corrosion pit was simulated using a finite element method. It was found that the stress concentration around corrosion pits increases with the corrosion level, depending on the pit dimensions with respect to the length of the corroded reinforcement.

Liu et al. [47] tested five pretensioned, partially prestressed concrete beams under fatigue loading. The initial prestressing action was approximately 0.75 times the strands' ultimate tensile strength $\left(\mathrm{f}_{\mathrm{ptk}}=1770 \mathrm{MPa}\right)$. The beams, artificially corroded up to $4 \%$ average mass loss, showed a great reduction in their deflection capacity, coupled with a variation in the failure mode from ductile to brittle. Moreover, after fatigue load, a degradation in the initial stiffness, coupled with a significant shortening of the post-yield branch, was observed as a consequence of the corrosion degradation.

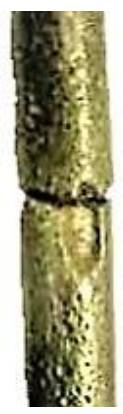

(a)

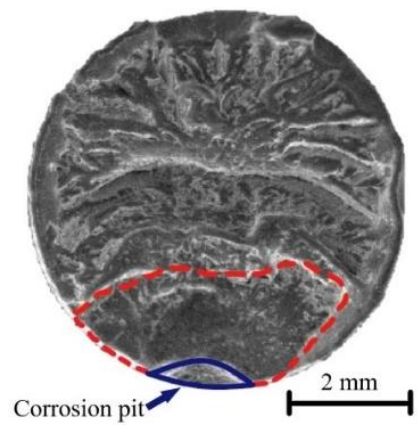

(b)

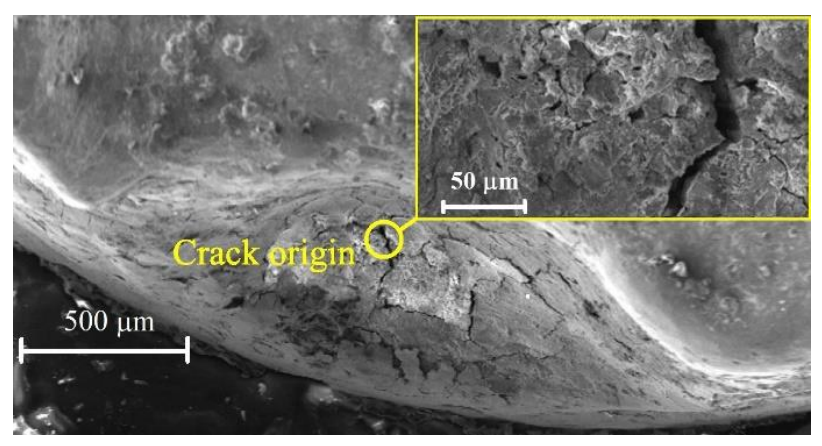

(c)

Figure 10. Experimental test by Zhang et al. [46]: (a) distribution of cross-sectional area of corroded prestressing wire, (b) SEM images of the fatigue fracture surface of the wire, and (c) SEM high-magnification image of the fatigue fracture surface. Adapted with permission from [46]. Copyright 2016 Construction and Building Materials.

To summarize the main outcomes of the collected research, the principal effects of strand corrosion on PRC beams are the change in the failure mode, characterized by the wire rupture, coupled with a progressive load-bearing capacity reduction, increasing the corrosion level. With the exception of [34,35], the corrosion level was not estimated in any 
of the studies investigating naturally deteriorated beams. Instead, in the case of beams damaged by mean accelerated corrosion, the evaluation of mass loss-or local cross-section reduction-is almost always provided.

Due to differences in the geometry of specimens, corrosion distribution along the beam, the degradation process or the lack of some crucial information, such as the corrosion level, most of the literature results are not directly comparable.

\section{Degradation Law of Flexural Strength for PRC Beams Subjected to Corrosion}

The collected experimental data are very different from each other in many aspects: beam dimensions, number of strands and their dimensions, pretension load level, material properties, type of degradation process, concrete-strand interaction and the position of corrosion along the strands. Most recently, it was observed that the mass loss can be considered only as an index of the severity of degradation since the beams' ultimate capacity is governed by the stress localization in the corrosion pit. Despite the complexity of the issue, an ongoing challenge is to define a degradation law for the flexural bearing capacity as a function of the average corrosion level that is able to provide an approximate indication of the expected residual bearing capacity of a PRC beam with a low corrosion level or severe corrosion. To ensure the applicability of a degradation law to an existing structure, an estimation of corrosion level is needed. Of course, the measurement of the corrosion level reached is a crucial issue. Since the estimation of CL is based on the Faraday law, several researchers have attempted to predict the corrosion rate, i.e. the current density developing in existing corroded RC structures. Critical reviews of some of the available models for the corrosion rate estimation of RC structures can be found in $[55,56]$. In these models, the current intensity is related to some factors affecting the corrosion: the concrete cover depth, the concrete quality (i.e. the concrete resistivity and the water-to-binder ratio), the cover cracking and the environmental aggressiveness (i.e. chloride content, temperature, $\mathrm{pH}$ and $\mathrm{RH}$ ). As a general rule, most of these parameters are difficult to define in existing structures. Therefore, some practical proposals to estimate CL based on the exposure class and the exposure duration have been developed [57], even if the range of variability of the current intensity associated with each exposure class is still high. With this aim, there has been important progress in developing new procedures based on non-destructive techniques for the estimation of the current intensity to assess corrosion levels [58-62].

In order to enhance the understanding of the structural performance degradation of corroded PRC beams, the collected experimental results have been here used in order to calibrate the bearing capacity degradation law with respect to the attained average corrosion level. For this purpose, among the experimental campaigns described above, the findings of five studies [29-33] cannot be included due to the lack of information on the attained corrosion level. In the other two works [38,43], the corrosion level is declared, but no information on the reference beam is provided. Therefore, the obtained results are not suitable for interpretation of the flexural strength degradation of corroded PRC beams. Concerning the work by Belletti and Vecchi [34,35], an average corrosion levelassessed by means of the weighted average of the corrosion levels measured along the prestressing strands according to [49]—is associated with each beam. From the considered experimental campaigns, the results of three beams from Belletti et al. [34] and one from Vecchi et al. [35] were excluded, as discussed in the previous section. Finally, due to the fatigue tests, the results obtained by Zhang and Liu cannot be employed [46,47]. As a conclusion, only the results of eight experimental campaigns can be considered as to the formulation of a conclusion [34-37,39,40,44,45]. Therefore, a total of 40 data related to corroded PRC beams are suitable for the aim of this study.

As indicated by the analysis of the experimental findings, high corrosion levels significantly reduce the bearing capacity and modify the failure mechanism. On the contrary, for low corrosion levels, the flexural strength could be kept invariant, showing instead a progressive ductility reduction. Between these two phases of flexural performance, 
a transition stage seems to exist. The presence of a transition stage was highlighted by Rinaldi et al. [36,37] according to the experimental results obtained relating to beams with both low and medium corrosion levels. Moreover, Dai et al. [28] achieved similar results through a theoretical model validated by three experimental campaigns.

The transition corrosion level should be characterized by a rather limited corrosion level coupled with a fragile collapse without significant strength decay. Performing a four-point bending test on corroded PRC beams up to failure, Rinaldi et al. [36,37] observed extremely brittle behavior in the case of the $7 \%$ corrosion level. Similar results were presented by Benenato et al. [44] for the $5.06 \%$ average mass loss. In addition, Menoufy and Soudki [39] observed a non-proportional reduction in ultimate load capacity exceeding the $5 \%$ mass losses with respect to the case of lower corrosion levels.

The in-depth analysis of the experimental outcomes, together with the state-of-the-art review, clearly shows that the evaluation of the structural performance of corroded PRC members is not a simple task, and the response depends on many parameters. A useful tool for an initial estimation of the corrosion impact on the residual capacity of PRC beams in flexure can be then given by a decay law able to synthesize the experimental literature results. In Figure 11, the ratio of the ultimate bending moment of corroded members $\left(M_{u, c o r r}\right)$ and uncorroded ones $\left(M_{u, 0}\right)$ is plotted versus the corresponding percentage of mass loss of corroded strands. A clear trend in the flexural strength decay can be observed in Figure 11. The decrease in the corrosion degree up to $7 \%$ of mass loss is well represented by a linear degradation law with a slight slope. A significant deterioration of the flexural capacity in the case of higher corrosion levels can be observed, and this is well represented by an exponential branch.

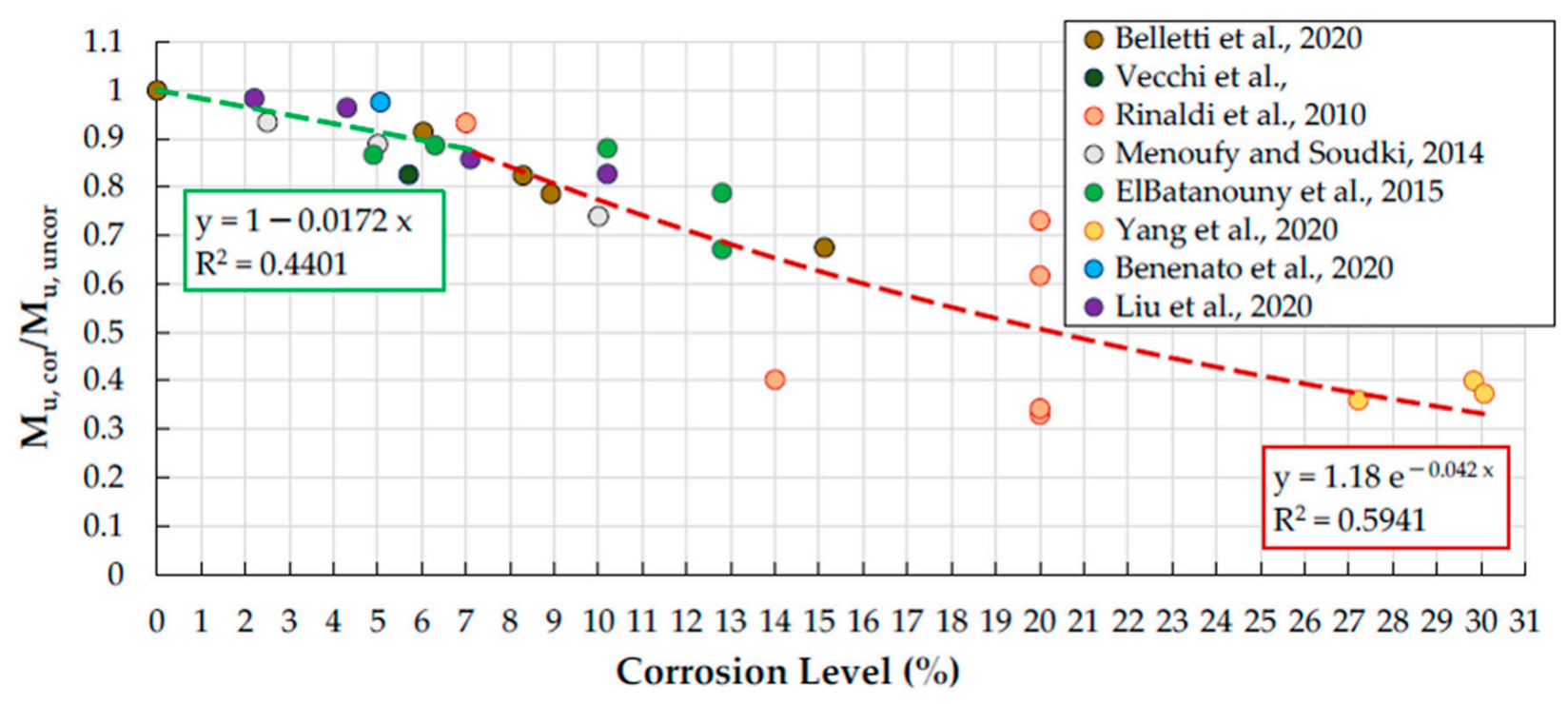

Figure 11. Impact of corrosion on residual moment capacity of PRC beams in flexure.

Regarding the presence of the transition phase, the residual ultimate moment ratio decreases according to a two-branch relationship, written as follows:

$$
\left\{\begin{array}{lrrr}
\frac{M_{u, \text { corr }}}{M_{u, 0}}=1-0.0172 \cdot C L & \text { for } & 0 \leq C L \leq 7 \% \\
\frac{M_{u, \text { orr }}}{M_{u, 0}}=1.18 \cdot e^{-0.042 C L} & \text { for } & C L>7 \%
\end{array}\right.
$$

As shown in Figure 12, the calibrated degradation law displays a similar trend to the ones obtained by the theoretical model presented by Dai et al. [28] for a specific beam, in which behavior is simulated considering a decay in both the strand-to-concrete interaction and the strand mechanical properties. However, the degradation law derived from the experimental results (Equation (1)) shows a higher reduction compared to that 
derived by the simulation of a specific beam, probably due to the fact that the experimental data come from different beams and various parameters can affect the degradation law.

It is important to underline that the simple proposed degradation law (Equation (1)) is based on the strong assumption that the strength degradation depends only on the average corrosion level of the strands. Therefore, the proposed law does not include fundamental parameters such as concrete strength, beam geometry, strand dimensions, confinement effect of the transversal steel bars and the level of pretension load. The present assumption has been made because the available data are not sufficient to be divided into homogenous families in order to investigate the influence of all the above-mentioned parameters. Therefore, further research providing additional experimental data is required to analyze homogenous data and, then, to reduce the high scatter of the experimental data, improving the degradation law for the ultimate bending moment ratio of corroded PRC beams. However, the proposed degradation law is a simple expression to provide initial information about the expected reduction in flexural bearing capacity for a deteriorated PRC beam once the corrosion level is assessed.

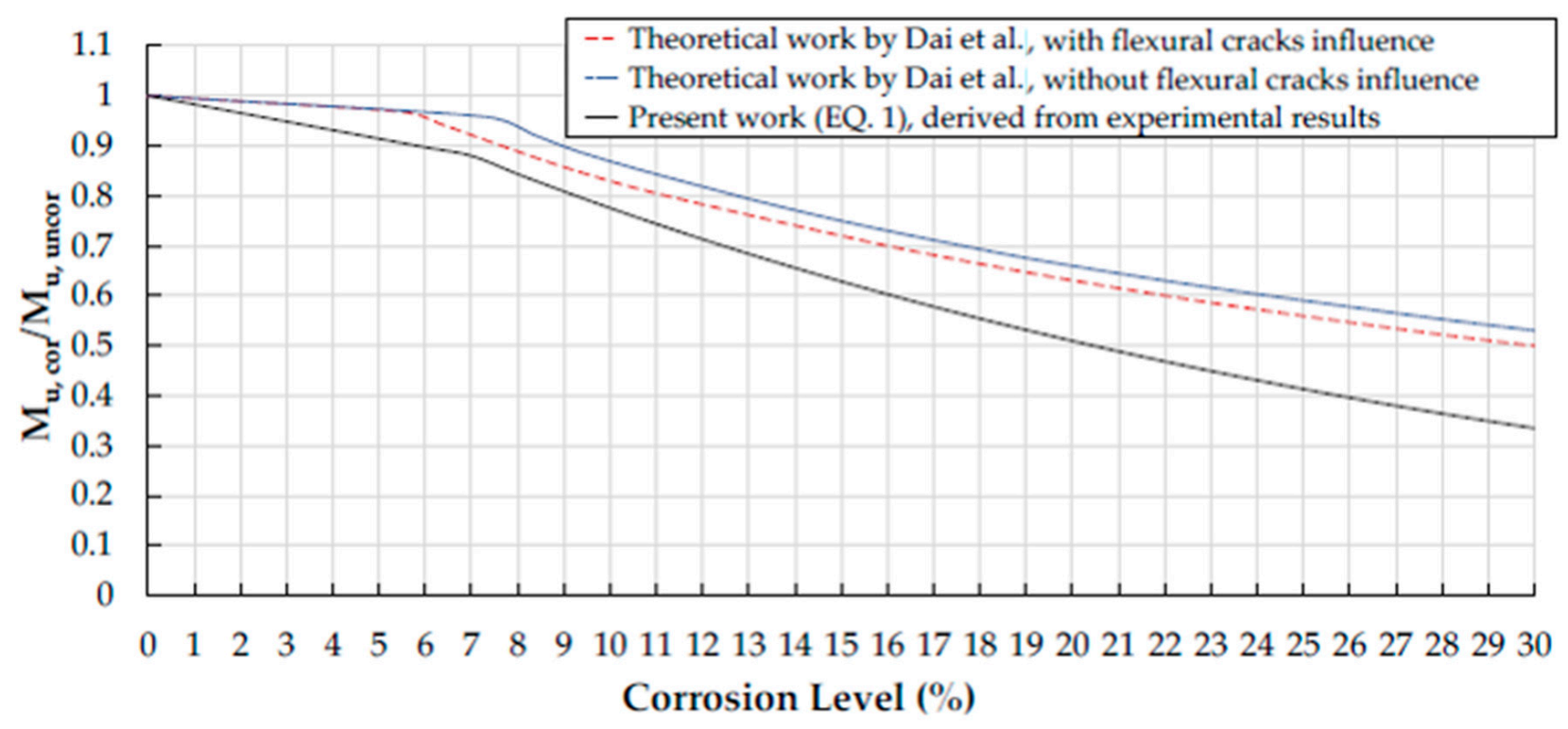

Figure 12. Comparison between the degradation laws derived from experimental results (Equation (1)) and the theoretical values proposed by Dai et al. [28].

\section{Conclusions}

In comparison with corroded RC beams, there are few experimental data available in the literature on the residual flexural capacity of prestressed corroded RC beams. The present paper provides an extensive review of all previously available experimental research on the load-bearing capacity of corroded PRC beams. The collected results have been used to calibrate a degradation law for the residual flexural strength with respect to the mass loss of strands. The main findings of the paper can be summarized as follows:

- Corrosion in PRC beams results in the formation of pitting corrosion in the strands. Stress concentration develops around the corrosion pits, which increases with the corrosion level and induces the premature failure of prestressing wires. Moreover, a reduction in the mechanical properties of the strand as a consequence of the pitting corrosion is expected.

- According to the collected experimental data, the main effect of strand corrosion on PRC beams was a change in the failure mode, characterized by the wires' rupture, coupled with a progressive load-bearing capacity reduction as a result of an increasing corrosion level. 
- Low corrosion levels induce a progressive ductility reduction without significant bearing-capacity losses; high corrosion levels cause a flexural strength reduction coupled with a failure mechanism modification. A transition stage between the two phases of the flexural performance of corroded PRC beams exists.

- An initial attempt has been made to relate the residual ultimate bending moment ratio - the ratio of the bending moment strength of a corroded beam $\left(M_{u, c o r r}\right)$ to an uncorroded beam $\left(M_{u, 0}\right)$ - to strands' mass loss (\%) as caused by corrosion. Even if a clear trend in flexural strength decay can be observed, due to the lack of sufficient and homogenous experimental data, the proposed relationship is not statistically representative.

- A database collecting the main experimental results on corroded PRC beams could help in defining a proper degradation law to predict residual load-bearing capacity.

Author Contributions: Conceptualization, M.K., S.I. and B.F.; methodology, M.K., S.I. and B.F.; validation, S.I. and A.B.; investigation, S.I., M.K. and A.B.; resources, M.K.; data curation, S.I., M.K. and B.F; writing—original draft preparation, M.K. and S.I.; writing—review and editing, M.K., S.I., A.B. and B.F.; visualization, B.F.; project administration, M.K. and S.I. All authors have read and agreed to the published version of the manuscript.

Funding: The work is part of the research project "OPTION-Effect of corrosion on prestressed reinforced concrete beam" between OsloMet-Oslo Metropolitan University and Niccolò Cusano University. OPTION has received funding from the Department of Civil Engineering and Energy Technology, OsloMet-Oslo Metropolitan University.

Institutional Review Board Statement: Not applicable.

Informed Consent Statement: Not applicable.

Data Availability Statement: Data sharing is not applicable to this article.

Acknowledgments: The authors thank Liu and Zhang for the permission granted to use selected images from Zhang et al. [46].

Conflicts of Interest: The authors declare no conflict of interest.

\section{References}

1. Hernández-Montes, E.; Fernández-Ruiz, M.A.; Carbonell-Márquez, J.F.; Gil-Martín, L.M. Residual capacity assessment of reinforced concrete D-Regions affected by corrosion. Constr. Build. Mater. 2020, 263, 120228. [CrossRef]

2. Kashani, M.M.; Maddocks, J.; Dizaj, E.A. Residual capacity of corroded reinforced concrete bridge components: State-of-the-art review. J. Bridge Eng. 2019, 24, 03119001. [CrossRef]

3. Kallias, A.N.; Rafiq, M.I. Performance assessment of corroding RC beams using response surface methodology. Eng. Struct. 2013, 49, 671-685. [CrossRef]

4. Lin, H.; Zhao, Y.; Feng, P.; Ye, H.; Ozbolt, J.; Jiang, C.; Yang, J.Q. State-of-the-art review on the bond properties of corroded reinforcing steel bar. Constr. Build. Mater. 2019, 213, 216-233. [CrossRef]

5. Benenato, A.; Imperatore, S.; Ferracuti, B. Mechanical Behaviour of Steel Reinforcement Damaged by Corrosion: A Review. In Proceedings of the 5th Workshop on The New Boundaries of Structural Concrete, Department of Civil and Environmental Engineering, Politecnico di Milano, Milan, Italy, 19-20 September 2019; Bamonte, P., Coppola, L., Ferrara, L., Gambarova, P.G., Eds.; IMREADY Publishing: Galazzano, San Marino, 2019.

6. Imperatore, S.; Rinaldi, Z.; Spagnuolo, S. Experimental investigations on the effects of the steel rebar corrosion at structural level. Struct. Concr. 2019, 20, 2230-2241. [CrossRef]

7. Bossio, A.; Imperatore, S.; Kioumarsi, M. Ultimate flexural capacity of reinforced concrete elements damaged by corrosion. Buildings 2019, 9, 160. [CrossRef]

8. Bossio, A.; Fabbrocino, F.; Monetta, T.; Lignola, G.P.; Prota, A.; Manfredi, G.; Bellucci, F. Corrosion effects on seismic capacity of reinforced concrete structures. Corros. Rev. 2019, 37, 45-56. [CrossRef]

9. Kioumarsi, M.M.; Hendriks, M.A.; Kohler, J.; Geiker, M.R. The effect of interference of corrosion pits on the failure probability of a reinforced concrete beam. Eng. Struct. 2016, 114, 113-121. [CrossRef]

10. Kioumarsi, M.; Baghban, M.H.; Imperatore, S. Effect of time dependent corrosion rate on residual capacity of corroded RC beam. In IOP Conference Series: Materials Science and Engineering, Proceedings of the 4th International Conference on Civil Engineering and Materials Science (ICCEMS 2019), Bangkok, Thailand, 17-19 May 2019; Volume 652, p. 012031. 
11. Proverbio, E.; Ricciardi, G. Failure of a 40 years old post-tensioned bridge near seaside. In Proceedings of the EuroCorr 2000, London, UK, 10-14 September 2000.

12. Costa, A.; Appleton, J. Case studies of concrete deterioration in a marine environment in Portugal. Cem. Concr. Compos. 2002, 24, 169-179. [CrossRef]

13. Helmerich, R.; Zunkel, A. Partial collapse of the Berlin Congress Hall on May 21st, 1980. Eng. Fail. Anal. 2014, 43, 107-119. [CrossRef]

14. Anania, L.; Badalà, A.; D'Agata, G. Damage and collapse mode of existing post tensioned precast concrete bridge: The case of Petrulla viaduct. Eng. Struct. 2018, 162, 226-244. [CrossRef]

15. Campione, G.; Giambanco, G. Analysis of a Collapsed Long-Span Reinforced Concrete Roof in South Italy: Design Mistakes and Material Degradation. J. Perform. Constr. Facil. 2020, 34, 04020001. [CrossRef]

16. Nagi, M.; Whiting, D. Corrosion of prestressed reinforcing steel in concrete bridges: State-of-the-art. Aci Spec. Publ. 1994, 151, $17-42$.

17. Nürnberger, U. Corrosion induced failure mechanisms of prestressing steel. Mater. Corros. 2002, 53, 591-601. [CrossRef]

18. Elices, M.; Caballero, L.; Valiente, A.; Ruiz, J.; Martin, A. Hydrogen embrittlement of steels for prestressing concrete: The FIP and DIBt tests. Corrosion 2008, 64, 164-174. [CrossRef]

19. Vehovar, L.; Kuhar, V.; Vehovar, A. Hydrogen-assisted stress-corrosion of prestressing wires in a motorway viaduct. Eng. Fail. Anal. 1998, 5, 21-27. [CrossRef]

20. Vu, N.A.; Castel, A.; François, R. Effect of stress corrosion cracking on stress-strain response of steel wires used in prestressed concrete beams. Corros. Sci. 2009, 51, 1453-1459. [CrossRef]

21. Carsana, M.; Bertolini, L. Corrosion failure of post-tensioning tendons in alkaline and chloride-free segregated grout: A case study. Struct. Infrastruct. Eng. 2015, 11, 402-411. [CrossRef]

22. Woodward, R.J.; Williams, F.W. Collapse of Yns-Y-Gwas Bridge, Glamorgan. Proc. Inst. Civ. Eng. 1988, 84, 635-669. [CrossRef]

23. Calvi, G.M.; Moratti, M.; O’Reilly, G.J.; Scattarreggia, N.; Monteiro, R.; Malomo, D.; Calvi, P.M.; Pinho, R. Once upon a time in Italy: The tale of the Morandi Bridge. Struct. Eng. Int. 2019, 29, 198-217. [CrossRef]

24. Nuti, C.; Briseghella, B.; Chen, A.; Lavorato, D.; Iori, T.; Vanzi, I. Relevant outcomes from the history of Polcevera Viaduct in Genova, from design to nowadays failure. J. Civ. Struct. Health Monit. 2020, 10, 87-107. [CrossRef]

25. Morgese, M.; Ansari, F.; Domaneschi, M.; Cimellaro, G.P. Post-collapse analysis of Morandi's Polcevera viaduct in Genoa Italy. J. Civ. Struct. Health Monit. 2020, 10, 69-85. [CrossRef]

26. Darmawan, M.S.; Stewart, M.G. Spatial time-dependent reliability analysis of corroding pretensioned prestressed concrete bridge girders. Struct. Saf. 2007, 29, 16-31. [CrossRef]

27. Zhang, D.; Zeng, Y.; Fang, M.; Jin, W. Service life prediction of precast concrete structures exposed to chloride environment. Adv. Civ. Eng. 2019, 2019. [CrossRef]

28. Dai, L.; Wang, L.; Bian, H.; Zhang, J.; Zhang, X.; Ma, Y. Flexural capacity prediction of corroded prestressed concrete beams incorporating bond degradation. J. Aerosp. Eng. 2019, 32, 04019027. [CrossRef]

29. Pape, T.M.; Melchers, R.E. The effects of corrosion on 45-year-old pre-stressed concrete bridge beams. Struct. Infrastruct. Eng. 2011, 7, 101-108. [CrossRef]

30. Pape, T.M.; Melchers, R.E. Performance of 45-year-old corroded prestressed concrete beams. Proc. Inst. Civ. Eng. Struct. Build. 2013, 166, 547-559. [CrossRef]

31. Rogers, R.; Wotherspoon, L.; Scott, A.N.; Ingham, J.M. Residual strength assessment and destructive testing of decommissioned concrete bridge beams with corroded pretensioned reinforcement. PCI J. 2012, 57, 100-118. [CrossRef]

32. Rogers, R. Assessing Pre-Tensioned Reinforcement Corrosion within the New Zealand Concrete Bridge Stock. Ph.D. Thesis, Department of Civil and Environmental Engineering, University of Auckland, Auckland, New Zeland, August 2016.

33. Mircea, D.; Ioani, A.; Filip, M.; Pepenar, I. Long-term durability of reinforced and prestressed elements in aggressive environments. Mater. J. 1994, 91, 135-140.

34. Belletti, B.; Rodríguez, J.; Andrade, C.; Franceschini, L.; Sánchez Montero, J.; Vecchi, F. Experimental tests on shear capacity of naturally corroded prestressed beams. Struct. Concr. 2020, 21, 1777-1793. [CrossRef]

35. Vecchi, F.; Belletti, B.; Franceschini, L.; Andrade, C.; Rodríguez, J.; Sánchez Montero, J. Flexural tests on prestressed beams exposed to natural chloride action. In Proceedings of the CACRCS DAYS 2020, Capacity Assessment of Corroded Reinforced Concrete Structures, Workshop On Line, 1-4 December 2020.

36. Rinaldi, Z.; Imperatore, S.; Valente, C.; Pardi, L. Influence of corrosion on prestressed concrete beams: An experimental survey. In Bridge Maintenance, Safety, Management and Life-Cycle Optimization, Proceedings of the Fifth International IABMAS Conference, Philadelphia, PA, USA, 11-15 July 2010; p. 392.

37. Rinaldi, Z.; Imperatore, S.; Valente, C. Experimental evaluation of the flexural behavior of corroded P/C beams. Constr. Build. Mater. 2010, 24, 2267-2278. [CrossRef]

38. Li, F.; Yuan, Y. Experimental study on bending property of prestressed concrete beams with corroded steel strands. J. Build. Struct. 2010, 31, 78-84. (In Chinese)

39. Menoufy, A.E.; Soudki, K. Flexural behavior of corroded pretensioned girders repaired with CFRP sheets. Pci J. 2014, 59, 129-143.

40. ElBatanouny, M.K.; Nanni, A.; Ziehl, P.H.; Matta, F. Condition Assessment of Prestressed Concrete Beams Using Cyclic and Monotonic Load Tests. ACI Struct. J. 2015, 112, 81-90. [CrossRef] 
41. Liu, Y.; Fan, Y. Experimental study on flexural behavior of prestressed concrete beams reinforced by CFRP under chloride environment. Adv. Civ. Eng. 2019. [CrossRef]

42. Yang, J.; Guo, T.; Li, A. Experimental investigation on long-term behavior of prestressed concrete beams under coupled effect of sustained load and corrosion. Adv. Struct. Eng. 2020, 23, 2587-2596. [CrossRef]

43. Dai, L.; Bian, H.; Wang, L.; Potier-Ferry, M.; Zhang, J. Prestress Loss diagnostics in pretensioned concrete structures with corrosive cracking. J. Struct. Eng. 2020, 146, 04020013. [CrossRef]

44. Benenato, A.; Ferracuti, B.; Imperatore, S.; Kioumarsi, M.; Spagnuolo, S. Behaviour of prestressed concrete beams damaged by corrosion. In Proceedings of the CACRCS DAYS 2020, Capacity Assessment of Corroded Reinforced Concrete Structures, Workshop On Line, 1-4 December 2020.

45. Liu, Y.; Fan, Y.; Yu, J.; Li, Q. Flexural behavior test of corroded prestressed concrete beams under chloride environment. Acta Mater. Compos. Sin. 2020, 37, 707-715. (In Chinese)

46. Zhang, W.; Liu, X.; Gu, X. Fatigue behavior of corroded prestressed concrete beams. Constr. Build. Mater. 2016, 106, 198-208. [CrossRef]

47. Liu, X.; Zang, W.; Ye, Z.; Gu, X. Structural behaviour of corroded pretensioned prestressed concrete beams subjected to high-cycle fatigue loading. J. Build. Struct. 2019, 40, 89-96. (In Chinese)

48. Moravcik, M.; Bujnakova, P.; Bahleda, F. Failure and damage of a first-generation precast prestressed bridge in Slovakia. Struct. Concr. 2020, 21, 2353-2362. [CrossRef]

49. Belletti, B.; Vecchi, F.; Bandini, C.; Andrade, C.; Montero, J.S. Numerical evaluation of the corrosion effects in prestressed concrete beams without shear reinforcement. Struct. Concr. 2020, 21, 1794-1809. [CrossRef]

50. Kioumarsi, M.; Hendriks, M.A.; Geiker, M. Failure probability of a corroded beam with interference effect of localised corrosion. Nord. Concr. 2015, 53, 39.

51. Kioumarsi, M.; Markeset, G.; Hooshmandi, S. Effect of pit distance on failure probability of corroded RC beam. Procedia Eng. 2017, 171, 526-533. [CrossRef]

52. Kioumarsi, M.M.; Hendriks, M.A.; Geiker, M.R. Effect of mesh alignment on simulated interference of localised corrosion on adjacent reinforcement rebars. In Proceedings of the XXII Nordic Concrete Research Symposium, Reykjavik, Iceland, 13-14 August 2014.

53. Kioumarsi, M.M.; Hendriks, M.A.; Geiker, M.R. Quantification of the interference of localised corrosion on adjacent reinforcement bars in a concrete beam in bending. Nord. Concr. Res. 2014, 49, 39-57.

54. Liu, X.; Zhang, W.; Gu, X.; Ye, Z. Probability distribution model of stress impact factor for corrosion pits of high-strength prestressing wires. Eng. Struct. 2021, 230, 111686. [CrossRef]

55. Otieno, M.B.; Beushausen, H.D.; Alexander, M.G. Modelling corrosion propagation in reinforced concrete structures-A critical review. Cem. Concr. Compos. 2011, 33, 240-245. [CrossRef]

56. Otieno, M.; Beushausen, H.; Alexander, M. Prediction of corrosion rate in reinforced concrete structures-a critical review and preliminary results. Mater. Corros. 2012, 63, 777-790. [CrossRef]

57. Rodriguez, J.; Andrade, C. CONTECVET. A Validated Users' Manual for Assessing the Residual Service Life of Concrete Structures: Manual for Assessing Corrosion-Affected Concrete Structures Geocısa, Madrid, Spain, 2001. EC Innovation Program. Report Number IN30902I. Available online: https:/ /www.ietcc.csic.es/wp-content/uploads/1989/02/manual_contecvet_ingles.pdf (accessed on 22 February 2021).

58. Andrade, C.; González, J.A. Quantitative measurements of corrosion rate of reinforcing steels embedded in concrete using polarization resistance measurements. Mater. Corros. 1978, 29, 515-519. [CrossRef]

59. Elsener, B.; Andrade, C.; Gulikers, J.; Polder, R.; Raupach, M. Half-cell potential measurements—Potential mapping on reinforced concrete structures. Mater. Struct. 2003, 36, 461-471. [CrossRef]

60. Andrade, C.; Alonso, C. Test methods for on-site corrosion rate measurement of steel reinforcement in concrete by means of the polarization resistance method. Mater. Struct. 2004, 37, 623-643. [CrossRef]

61. Poursaee, A. Corrosion measurement and evaluation techniques of steel in concrete structures. In Corrosion of Steel in Concrete Structures; Woodhead Publishing: Sawston, Cambridge, UK, 2016; pp. 169-191.

62. Luo, D.; Li, Y.; Li, J.; Lim, K.S.; Nazal, N.A.M.; Ahmad, H. A recent progress of steel bar corrosion diagnostic techniques in RC structures. Sensors 2019, 19, 34. [CrossRef] [PubMed] 